\title{
Independent effects of stimulus and cycle duration in conditioning: The role of timing processes
}

\author{
KIMBERLY KIRKPATRICK and RUSSELL M. CHURCH \\ Brown University, Providence, Rhode Island
}

\begin{abstract}
Rats received delay conditioning procedures with a white-noise conditioned stimulus (CS), a food unconditioned stimulus (US), and head entries into the food cup as the conditioned response. The stimulus duration $(S)$ and the interval between food deliveries $(C)$ were varied between groups: $S=15,30$, 60 , and $120 \mathrm{sec} ; C=90,180$, and $360 \mathrm{sec}$. The stimulus/cycle duration ratio was negatively related to the asymptotic level of conditioning but had no effect on the rate of acquisition. Conditioning and timing of responses emerged together in training. Timing occurred during the CS-US interval (ISI) and the US-US interval (ITI), as evidenced by increasing response rate gradients that were steeper for shorter intervals. The effects of the stimulus/cycle ratio on conditioning were attributed to independent timing of the $S$ and $C$ durations. Serial-, parallel-, and single-process accounts of conditioning and timing are compared.
\end{abstract}

Two temporal variables that affect the acquisition of conditioned responding in a delay conditioning procedure are the stimulus duration (the interval from conditioned stimulus [CS] onset to unconditioned stimulus [US] delivery) and the cycle duration (the time between successive US deliveries). The strength and rate of conditioning are inversely related to stimulus duration in several paradigms, including nictitating membrane in rabbits (Salafia, Terry, \& Daston, 1975; Schneiderman \& Gormezano, 1964), shuttlebox avoidance in goldfish (Bitterman, 1964) and rats (Black, 1963), and autoshaping in pigeons (Gibbon, Baldock, Locurto, Gold, \& Terrace, 1977). The effect of cycle duration has often been characterized as a trial spacing effect, wherein longer durations between successive US presentations result in faster rates and stronger levels of conditioning to the CS (Domjan, 1980; Gibbon et al., 1977; Salafia et al., 1975; Terrace, Gibbon, Farrell, \& Baldock, 1975).

Gibbon and colleagues (Gibbon et al., 1977; Gibbon \& Balsam, 1981; Terrace et al., 1975) discovered that conditioned responding to a keylight stimulus in a pigeon autoshaping paradigm (Brown \& Jenkins, 1968) was determined by the ratio of the stimulus and cycle durations. They demonstrated that the number of cycles required for the acquisition of keypecking (one or more keypecks during three out of four successive stimuli; Gibbon \& Balsam, 1981, Figure 7.2) was positively related to the stimulus/cycle $(S / C)$ duration ratio, so that fewer cycles were required to meet the acquisition criterion with smaller $S / C$ ratios. (Gibbon \& Balsam, 1981,

This research was supported by National Institute of Mental Health Grant MH44234 to Brown University. Correspondence should be addressed to K. Kirkpatrick, Department of Psychology, Box 1853, Brown University, Providence, RI 02912 (e-mail: kim_kirkpatrick@brown. edu). actually used the cycle/stimulus ratio, which resulted in an inverse relationship with cycles to acquisition criterion.) Recent studies have also reported the $S / C$ ratio effect in a goal-tracking paradigm in rats (Holland, 2000; Lattal, 1999).

To explain the $S / C$ ratio effect on conditioning, Gibbon and Balsam (1981; and, later, Gallistel \& Gibbon, 2000) proposed a two-stage model in which acquisition of conditioned responding to a stimulus (an increase in the rate or probability of responding during the stimulus as a function of training) occurred first and timing of the stimulus duration (an increase in the rate or probability of responding over the duration of the stimulus) occurred much later.

In the conditioning mechanism proposed by Gibbon and Balsam (1981), a given reinforcer supports a certain total expectancy, $H$, that is spread uniformly over the duration of the stimulus and over the duration of the cycle. This creates expectation densities for the stimulus $\left(h_{S}\right)$ and cycle $\left(h_{C}\right)$ :

$$
h_{S}=H / S
$$

and

$$
h_{C}=H / C
$$

Because the total expectation $(H)$ is the same during the stimulus $(S)$ and cycle $(C)$, the expectation densities $\left(h_{S}\right.$ and $h_{C}$ ) are inversely related to the durations of the intervals (stimulus or cycle). The decision of whether to respond to a given stimulus is determined by the value of the ratio of the heights of the two expectation densities:

$$
r=h_{S} / h_{C}=S / C \text {. }
$$

If $r$ exceeds a threshold, $b$, then responding will emerge to the stimulus. 
According to the Gibbon and Balsam (1981) proposal, after the conditioning mechanism results in a decision to respond to a stimulus, acquisition of timing of that stimulus may begin. The timing mechanism that was proposed by Gibbon and Balsam is scalar expectancy theory (SET; Gibbon, 1977). In the information processing version of SET (Gibbon \& Church, 1984; Gibbon, Church, \& Meck, 1984), a pacemaker emits pulses at random with some mean rate; the pulses are sent to an accumulator that stores the total number of pulses since the onset of the stimulus. At the time of reinforcement, the total number of pulses in the accumulator is multiplied by a constant and stored as an element in reference memory. This reference memory consists of an unorganized collection of elements based on previously reinforced occasions. The decision of when to respond in the stimulus is controlled by a ratio comparison between the number of pulses in the currently elapsing interval and a random sample of a single element from reference memory. When the ratio passes a threshold, responding is initiated. Thus, the probability of responding increases as elapsed time in the current interval comes to approximate a remembered time of reinforcement, reaching a maximum near the expected moment of reinforcement delivery.

There are three major predictions of Gibbon and Balsam's (1981) model that are the primary focus of this article.

1. The $S / C$ ratio affects the rate of acquisition of conditioned responding. The comparator mechanism for conditioning predicts that the $S / C$ ratio will affect the number of cycles to reach an absolute performance criterion. Larger ratios will produce larger levels of $r$ given a certain number of reinforcers have been delivered, resulting in fewer cycles to reach any absolute performance criterion when the $S / C$ ratio is small. Prior studies that have reported the $S / C$ ratio effects on the rate of acquisition of conditioned responding have used an absolute response criterion. An absolute performance criterion does not distinguish between differences in the rate and the asymptotic level of conditioning. Suppose, for example, that calculations were made of the number of cycles required to reach an absolute criterion of responding during $75 \%$ of the stimuli. If one group required 50 reinforced stimulus presentations to reach a stable asymptote of $80 \%$, then the performance criterion would likely be reached within 50 presentations or less. However, if a second group required 50 reinforced stimulus presentations to reach a stable asymptote of $60 \%$, then the absolute performance criterion would be reached beyond 50 presentations. Thus, two groups with the same rate of learning to reach different asymptotic levels could be mistakenly identified as having different rates of learning if an absolute performance criterion were used.

2. The $S / C$ ratio is the primary predictor of the acquisition of conditioned responding, with no contribution of the component stimulus and cycle durations. According to the Gibbon-Balsam (1981) model, the strength of conditioned responding, given a certain number of rein- forced stimulus presentations, would be invariant if the $S / C$ ratio is held constant. However, Holland (2000) reported a failure of ratio invariance in groups of rats that received a common $S / C$ ratio of $1 / 6$ made up of different stimulus and cycle interval pairs. When the $S / C$ ratio was made up of shorter durations, the strength of conditioning was greater than when the $S / C$ ratio was made up of longer durations. This lack of ratio invariance indicates that there are effects of the stimulus and cycle durations on the strength of conditioning that is observed, but the degree of the contribution of the individual stimulus and cycle intervals needs to be determined.

3. The timing mechanism does not participate in the $S / C$ ratio effect on conditioning. Because the GibbonBalsam (1981) model is a serial model in which conditioning occurs before timing, timing of the stimulus and cycle durations is assumed to play no role in the emergence of conditioned responding. The emergence of conditioning and timing of responding has not been directly compared, but there is suggestive evidence that conditioning and timing may emerge together. Gibbon et al. (1977, Figures 5 and 11) reported temporal gradients of responding during the stimulus as a function of training. Of the 33 groups, 21 produced temporal gradients that clearly increased over the duration of the signal by the end of training. In 19 of these 21 cases, the temporal gradients were well established in the first session containing responses on at least 10 of the 25 trials and changed only modestly after 20 additional training sessions. Timing of conditioned responses has been also reported in the rat goal-tracking paradigm after limited amounts of training (Holland, 2000) and in a conditioned freezing paradigm after only a single shock exposure (Bevins \& Ayres, 1995; Maes \& Vossen, 1992). The fact that timing can be observed after only a single experience indicates that timing mechanisms may operate early in the acquisition process.

If timing does occur early in training, then it is possible that timing mechanisms may participate in the $S / C$ ratio effects on conditioning. This proposal is reasonable, given that (1) temporal relationships between CSs and USs are learned in simultaneous, backward, higher order conditioning, sensory preconditioning, trace, and delay conditioning paradigms (Barnet, Arnold, \& Miller, 1991; Barnet, Cole, \& Miller, 1997; Cole, Barnet, \& Miller, 1995; Matzel, Held, \& Miller, 1988; Savastano \& Miller, 1998) and (2) pigeons can discriminate between pairs of intervals that differ in the ratio of their durations (Dreyfus, Fetterman, Smith, \& Stubbs, 1988; Fetterman \& Dreyfus, 1986, 1987). Nonetheless, timing mechanisms have not received serious consideration in the $S / C$ ratio effects on the acquisition of conditioning because of the presumption that timing typically emerges well after conditioning.

Accordingly, the present study involved manipulations of the $S / C$ ratio and examined these three predictions of the Gibbon-Balsam (1981) model. Two discrimination ratios (DRs) were compared over the course of training: a stimulus DR and a temporal DR (see Figure 1 and Equa- 


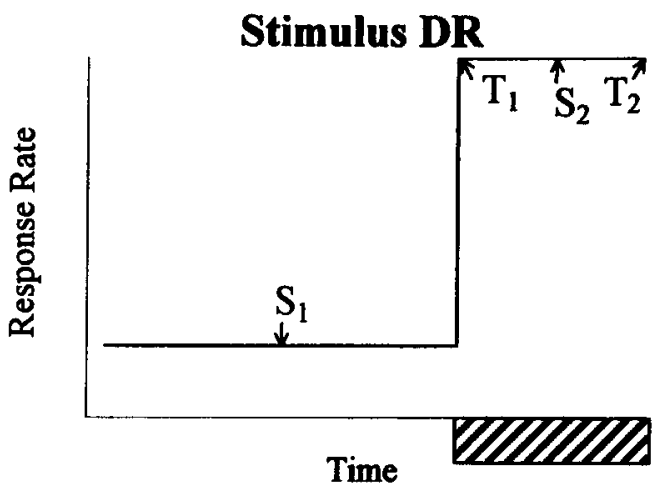

Temporal DR
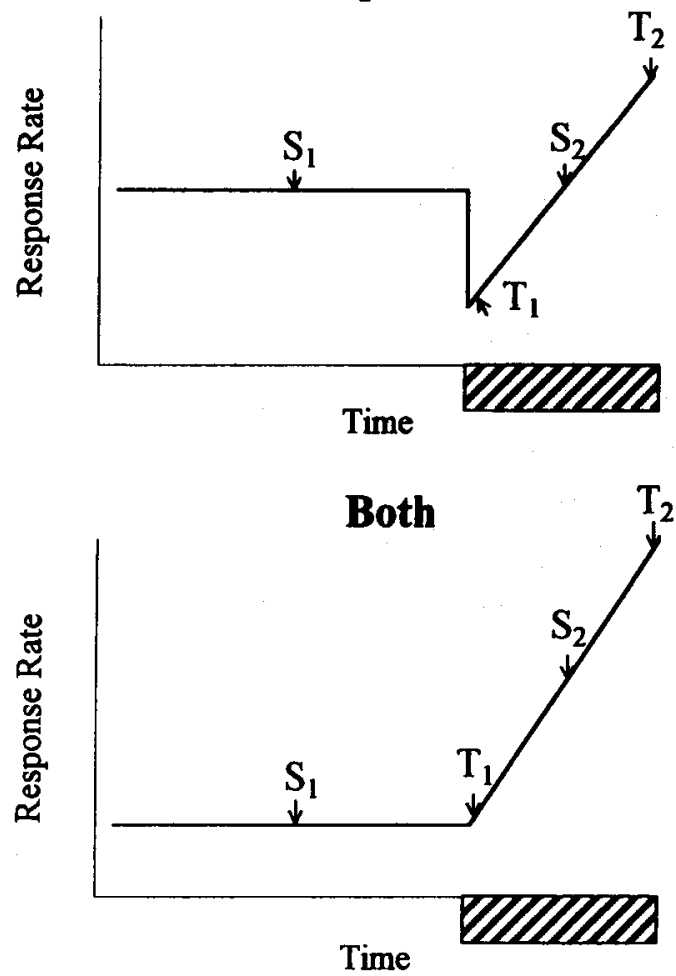

Figure 1. The components of the stimulus discrimination ratio ( $S_{1}$ and $S_{2}$ ) used in Equation 3a and temporal discrimination ratios $\left(T_{1}\right.$ and $\left.T_{2}\right)$ used in Equation $3 \mathrm{~b}$ given different response patterns. The hatched rectangle marks the stimulus period. Top panel: A hypothetical response rate function produced by a process that would result in an above-chance stimulus discrimination ratio, but a chance-level temporal discrimination ratio. Middle panel: A hypothetical response rate function that would result in an above-chance temporal discrimination ratio, but a chancelevel stimulus discrimination ratio. Bottom panel: $\mathbf{A}$ hypothetical response rate function that would result in above-chance stimulus and temporal discrimination ratios.

tions $3 \mathrm{a}$ and $3 \mathrm{~b}$ ). The stimulus DR served as the measure of conditioning to the stimulus (vs. the nonstimulus), and the temporal DR served as a measure of timing of the stimulus duration. Additional analyses were conducted on the temporal gradients of responding during the stimulus and nonstimulus periods.

$$
\text { Stimulus DR }=S_{2} /\left(S_{1}+S_{2}\right)
$$

and

$$
\text { Temporal DR }=T_{2} /\left(T_{1}+T_{2}\right)
$$

The effect of the $S / C$ ratio on conditioning and timing of responses was assessed using measures of the speed of acquisition and asymptotic level of the stimulus and temporal DRs. The number of cycles to reach a relative performance criterion was examined to determine whether the $S / C$ ratio effects were on the rate of acquisition or asymptotic level or conditioning, or both. The contribution of the stimulus and cycle durations was examined, and the effect of their ratio was assessed. Finally, the role of timing in the emergence and maintenance of conditioned responding was determined. The emergence of the stimulus and temporal DRs was compared to see whether timing was evident early in training and whether timing and conditioning emerged separately or together. If the stimulus DR was acquired before the temporal DR (Figure 1, top panel), one would expect that, early in training, there would be a higher rate of responding in the stimulus than in the nonstimulus $\left(S_{2}>S_{1}\right)$ but no change in the rate of responding over the course of the stimulus $\left(T_{2}=T_{1}\right)$. If the temporal DR was acquired before the stimulus DR (Figure 1, middle panel), there would be no change in the average rate of responding between the stimulus and nonstimulus periods $\left(S_{2}=S_{1}\right)$, but there would be a higher response rate at the end of the stimulus than at the beginning $\left(T_{2}>T_{1}\right)$. A final possibility is that the stimulus and temporal DRs could emerge together (Figure 1, bottom panel), which would result in higher rates of responding in the stimulus than in the nonstimulus $\left(S_{2}>\right.$ $S_{1}$ ) and higher response rates late in the stimulus than early in the stimulus $\left(T_{2}>T_{1}\right)$.

Additional analyses were conducted to examine the contribution of timing to the $S / C$ ratio effects on conditioned responding. The results are discussed in the context of the Gibbon-Balsam (1981) serial-process model, as well as alternative parallel- and single-process models.

\section{METHOD}

\section{Subjects}

Forty-eight male Sprague-Dawley rats (Taconic Laboratories, Germantown, NY) were housed individually in a colony room on a 12:12-h light:dark cycle (lights off at 8:45 a.m.). Dim red lights provided illumination in the colony room when the fluorescent lights were off and at all times when the rats were in the testing room. The rats were fed a daily ration that consisted of $45-\mathrm{mg}$ Noyes pellets (Improved Formula A, Lancaster, $\mathrm{NH}$ ) that were delivered during the experimental session, and an additional $15 \mathrm{~g}$ of FormuLab 5008 (PMI Nutrition International, Brentwood, MO) food was given in the home cage shortly after the daily sessions. Water was available ad lib in both the home cages and the experimental chambers. The rats arrived in the colony at 49 days of age and were handled daily until the beginning of the experiments. The rats were tested in two 
sets of 24 rats each. Training of the first set of rats began when they were 67 days old; training of the second set began when the rats were 74 days old. All other aspects of their treatment were the same as for the first set.

\begin{abstract}
Apparatus
Each of the 12 chambers $(25 \times 30 \times 30 \mathrm{~cm})$ was located inside of a ventilated, noise-attenuating box $(74 \times 38 \times 60 \mathrm{~cm})$. A chamber was equipped with a food cup, a water bottle, a speaker, and a houselight. A magazine pellet dispenser (Model ENV-203, Med Associates, St. Albans, VT) delivered $45-\mathrm{mg}$ Noyes (Lancaster, $\mathrm{NH}$ ) pellets into the food cup. Each head entry into the food cup was transduced by an LED photocell. Head entries constituted the dependent variable. The water bottle was mounted outside the chamber; water was available through a tube that protruded through a hole in the back wall of the chamber. The speaker for delivering white noise was situated above and to the left of the water tube, and the houselight was located above and to the right of the water tube. Two Gateway 486 DX2/66 computers running the Med-PC Medstate Notation Version 2.0 (Tatham \& Zurn, 1989) controlled experimental events and recorded the time at which events occurred with $10-\mathrm{msec}$ resolution.
\end{abstract}

\section{Procedure}

Training and testing of all rats occurred during 105 -min sessions. The rats were tested in two different sets of 24 rats each. Each set of rats was randomly divided into three groups of 8 , with groups identified by their $S / C$ ratio: Set 1 contained Groups $30 / 180$, $60 / 180$, and 120/180; Set 2 contained Groups 15/180, 60/90, and $60 / 360$. Thus, for Group 15/180, the stimulus was present during the $15 \mathrm{sec}$ immediately preceding the food delivery, and the interval between successive food deliveries (the cycle) was $180 \mathrm{sec}$.

Original training. Each of the six groups of rats received different stimulus and cycle durations. Four groups received a cycle duration of $180 \mathrm{sec}$, but with different stimulus durations of 15,30 , 60 , or $120 \mathrm{sec}$, creating $S / C$ ratios of $8.3,16.7,33.3$, or 66.7 , respectively, with the $S / C$ ratio here being defined as (stimulus duration/cycle duration) $\times 100$. Two additional groups received a stimulus duration of $60 \mathrm{sec}$ and cycle durations of 90 or $360 \mathrm{sec}$. (Group $60 / 180$ served as a comparison with these two groups.) This created $S / C$ ratios of $16.7,33.3$, or 66.7 . Half of the rats in each condition, randomly selected, received a houselight, and half of the rats in each condition received a $70-\mathrm{dB}$ white noise during the stimulus period. The nonstimulus period (the interval between food delivery and the onset of the stimulus period) was filled with white noise in the groups that received the houselight during the stimulus period and was filled with the houselight in the groups that received the white noise during the stimulus period. The cycle, stimulus, and nonstimulus durations were all constant. The food was a single $45-\mathrm{mg}$ food pellet. Food delivery occurred at the end of the stimulus period in all conditions. Original training lasted for 40 sessions, which resulted in the delivery of 680 cycles to Group $60 / 360,1,360$ cycles to Groups $15 / 180,30 / 180,60 / 180$, and $120 / 180$, and 2,720 cycles to Group 60/90.

Stimulus omission test. Groups $15 / 180,60 / 90$, and $60 / 360$ received a test phase that consisted of $80 \%$ of the same cycles as in original training and $20 \%$ of the cycles delivered without either the light or the noise in the stimulus and nonstimulus periods. These stimulus omission cycles had the same duration as the normal cycles, but there was no houselight (or white noise) during the nonstimulus period, and there was no white noise (or houselight) during the stimulus period. Testing with the stimulus omission cycles continued for 20 sessions.

Peak procedure. Following original training, Groups 120/180, $60 / 180$, and $30 / 180$ were transferred to a peak procedure; Groups $15 / 180,60 / 90$, and $60 / 360$ received a peak procedure after the stimulus omission test. On $75 \%$ of the cycles, the rats received the conditions of original training, with the same cycle and stimulus durations. On the remaining $25 \%$ of the cycles, the rats received either a white noise or a houselight that was four times the normal duration and ended without food delivery; the signal during peak intervals was the same as the signal that filled the stimulus period during training. A new cycle began at the end of the long stimulus. Peak procedure training lasted for 20 sessions.

\section{Data Analysis}

The time of occurrence of each head entry into the food cup (each time the photobeam was interrupted), the time of each food reinforcement, and the time of onset and termination of each whitenoise and houselight presentation were recorded. All analyses of original training were conducted on the first 680 food-food cycles received by the rats. Because of the limited number of observations in the testing sessions, all stimulus omission and peak procedure probes were analyzed.

Discrimination ratios. For the assessment of timing and conditioning to the stimulus, the rate of responding in four windows was determined for each cycle. The duration of all of the windows was $2 / 15$ of the stimulus duration. For calculation of conditioning to the stimulus (the stimulus DR), window $S_{1}$ was centered around the middle of the nonstimulus period, and window $S_{2}$ was centered around the middle of the stimulus period (Figure 1). The response rates were determined in each window and used Equation $3 \mathrm{a}$ (see introduction).

For the assessment of timing of the duration of the stimulus period (the temporal DR), window $T_{1}$ began immediately after stimulus onset, and window $T_{2}$ ended at the time of stimulus termination (Figure 1). The response rates were determined in each window and used Equation $3 b$ (see introduction).

The stimulus and temporal DRs could range from 0 to 1 , with 0.5 indicating that the rate of responaing in the two windows was equal. If there was no response in either window, the cycle was recorded as empty. The window size was made proportional to stimulus duration because shorter stimuli resulted in higher rates of responding, which resulted in more empty windows of any fixed duration for longer intervals than for shorter ones. The proportional window size resulted in an approximately constant percentage $(M=32.5 \%$ $\pm 0.04 \%$ ) of empty windows across the different groups.

Low-high algorithm. Because acquisition of the stimulus and temporal DRs resembled a step function in the vast majority of rats, the DRs on individual cycles were analyzed with a low-high algorithm that identified the point of transition from near-chance DRs to near-asymptotic DRs. The low-high analysis was conducted separately for the stimulus and temporal DRs produced by each rat. The algorithm stepped through successive cycles in the training phase, determining the mean DR across all cycles preceding the current cycle and the mean DR across all cycles following the current cycle. The transition point was identified as the cycle at which the maximum difference between the mean DR before and after the current cycle occurred. There were no restrictions on the level of the mean DRs before and after the transition point, except that the mean DR after the transition had to exceed the mean DR before the transition.

Local response rate. Calculations of the number of responses $\left(n_{r}\right)$ and the number of opportunities to respond $\left(n_{0}\right)$ were conducted in each $1-\mathrm{sec}$ interval following food delivery or stimulus onset. The number of responses in each $1-\sec$ interval was summed during each second over all cycles in the analysis. Because the intervals were fixed, the number of opportunities to respond in each $1-\mathrm{sec}$ interval was equal to the total number of cycles included in the analysis. Local rate, expressed as responses per minute, was then defined in each 1-sec interval as: $60\left(n_{\mathrm{r}} / n_{\mathrm{o}}\right)$.

Partial correlations. Partial correlation coefficients were conducted to assess the effect of stimulus duration, cycle duration, and the $S / C$ ratio on various measures of performance. The partial cor- 

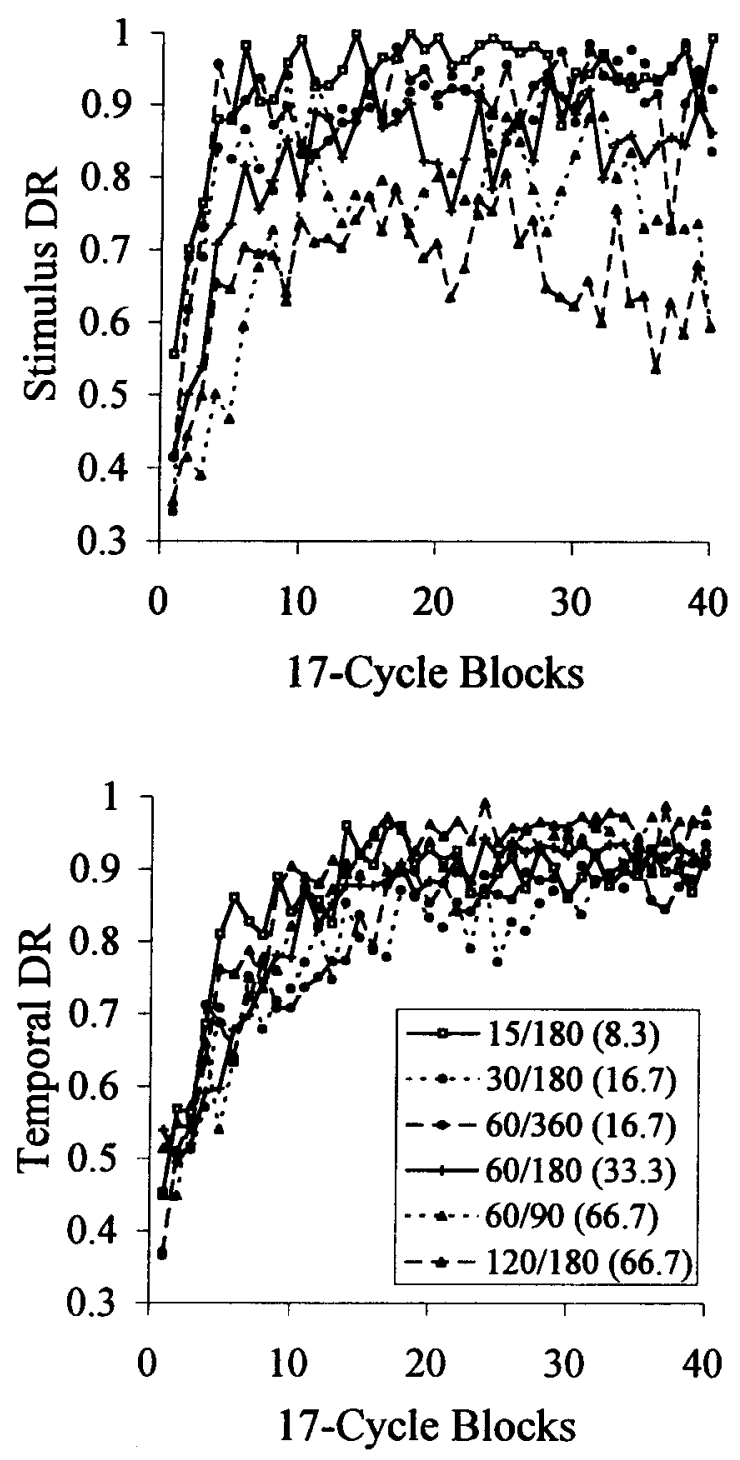

Figure 2. Acquisition of stimulus (top panel) and temporal (bottom panel) discrimination ratios as a function of 17-cycle blocks of training. Each group of rats is designated by the stimulus and cycle durations, with the stimulus/cycle $(S / C)$ ratio indicated in parentheses.

relation coefficient measures the strength of the linear relationship between $X$ (e.g., stimulus duration) and $Y$ (e.g., response rate), while controlling for one or more variables (e.g., cycle duration) that may influence that relationship (e.g., Hays, 1997). Partial correlations were necessary because there were three different cycle durations delivered to groups that received a common stimulus duration of $60 \mathrm{sec}$ and four different stimulus durations delivered to groups that received a common cycle duration of $180 \mathrm{sec}$. If both cycle duration and stimulus duration were linearly related to responding, then a simple correlation of, for example, stimulus duration with response rate would be influenced by the linear relationship between cycle duration and response rate. For the analysis of the relationship between stimulus duration and responding, the partial correlations controlled for variations in cycle duration, the partial correlations between cycle duration and responding controlled for variations in stimulus duration, and the partial correlations be- tween $S / C$ ratio and responding controlled for both stimulus and cycle duration.

\section{RESULTS}

\section{Original Training}

Emergence of conditioning and timing. The acquisition of the stimulus and temporal DRs is portrayed in top and bottom panels of Figure 2, respectively, for each of the six groups of rats as a function of 17-cycle blocks of training.' The DRs were collapsed across stimulus modality (noise or light) because modality had no reliable effect [stimulus DR, $t(46)=1.1$; temporal DR, $t(46)=$ $0.5]$. The stimulus DRs appeared to be affected by the $S / C$ ratio. When the stimulus occupied $66.7 \%$ of the total cycle duration (Groups 60/90 and 120/180), performance was poorer than when the stimulus occupied a lower percentage of the cycle. In contrast, the temporal DRs increased at about the same rate and to about the same asymptote in all six groups.

To assess the nature of the effects of the $S / C$ ratio on the acquisition of the stimulus and temporal DRs, the data shown in Figure 2 were fit by exponential functions with parameters for the slope and asymptote. These comparisons were conducted separately for the stimulus and temporal DRs. Between-group differences in the slope of the fits would suggest differences in the rate of learning, whereas differences in the asymptote of the fits would indicate differences in the asymptotic level of performance. Table 1 displays the parameters of the best-fitting exponential equation for the stimulus and temporal DRs. There was a negative correlation between the $S / C$ ratio and the asymptote of the exponential fit to the stimulus DR functions $(r=-.95, p<.01)$, but there was no apparent effect of $S / C$ ratio on the slope of the stimulus DR functions $(r=-.20)$.

There was a positive correlation between $S / C$ ratio and the asymptote of the exponential fits to the temporal DR functions $(r=.82, p<.05)$; except for Group $15 / 180$, there was a trend for higher $S / C$ ratios to yield higher asymptotic temporal DRs in the exponential fits. The correlation between the $S / C$ ratio and the asymptotic fits to the temporal DRs appeared to be due to a failure of the DRs to achieve a level asymptote by the end of training. As a result, the asymptotes for the exponential fits occurred beyond the last session of training for some groups. This problem did not occur in the exponential fits to the

Table 1

Asymptote and Slope Parameters for Exponential Fits to the Stimulus and Temporal DRs in Figure 2

\begin{tabular}{lcccccc}
\hline & & \multicolumn{2}{c}{ Stimulus DR } & & \multicolumn{2}{c}{ Temporal DR } \\
\cline { 3 - 4 } Group & $S / C$ Ratio & Asymptote & Slope & & Asymptote & Slope \\
\hline $15 / 180$ & 8.3 & 0.95 & 0.72 & & 0.90 & 0.49 \\
$30 / 180$ & 16.7 & 0.91 & 0.59 & & 0.84 & 0.39 \\
$60 / 360$ & 16.7 & 0.91 & 0.68 & & 0.85 & 0.42 \\
$60 / 180$ & 33.3 & 0.86 & 0.50 & & 0.91 & 0.30 \\
$60 / 90$ & 66.7 & 0.78 & 0.37 & & 0.93 & 0.27 \\
$120 / 180$ & 66.7 & 0.68 & 0.83 & & 0.95 & 0.33 \\
\hline
\end{tabular}



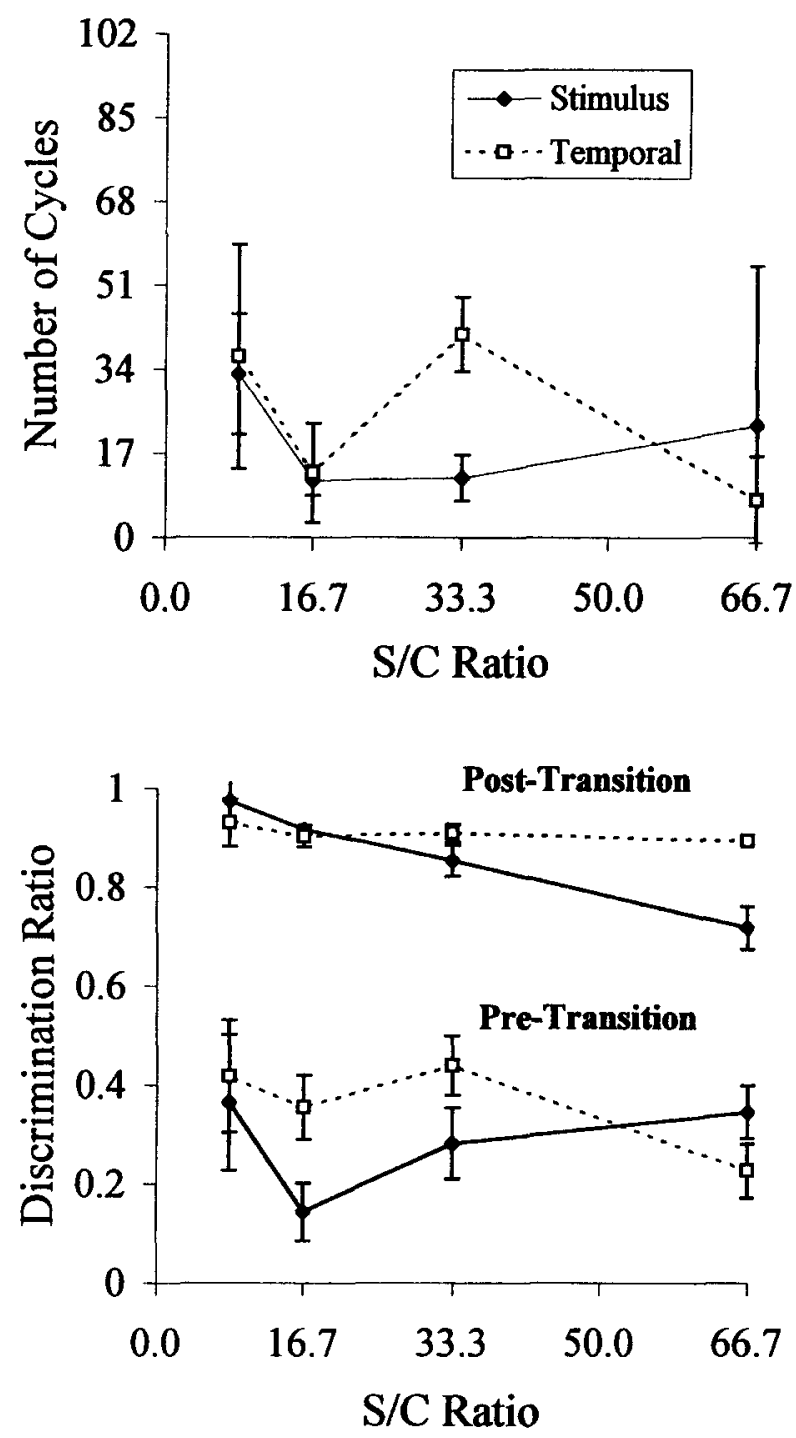

Figure 3. Top panel: The number of cycles before a transition occurred from low to high discrimination ratios for the stimulus and temporal measures as a function of the stimulus/cycle $(S / C)$ ratio. Bottom panel: Pretransition and posttransition stimulus and temporal discrimination ratios. Each point in the figure is the mean of all rats receiving a particular $S / C$ ratio, plus or minus the standard error of the mean.

stimulus DRs, which may have been due to the fact that timing appeared to gradually improve after asymptotic levels were reached in the stimulus DRs. There also was a hint of a relationship between the $S / C$ ratio and the slope of the functions, but it did not achieve statistical significance $(r=-.81, p=.06)$.

Point of learning of conditioning and timing. While the mean DR functions demonstrated acquisition of both conditioning and timing over the course of training, this analysis does not identify the point in training at which conditioning to the stimulus and timing of the stimulus first occurred. For this, an analysis of the point of learn- ing of the stimulus and temporal DRs was conducted at the individual-cycle level.

Inspection of the data from individual rats revealed that there was a tendency to produce DRs near chance early in training, but then, at some point, there was a sharp transition so that the DRs were near the asymptotic level. ${ }^{2} \mathrm{~A}$ point of transition from near-chance DRs to nearasymptotic DRs was identified using a low-high algorithm (see Data Analysis section). The top panel of Figure 3 shows the number of cycles before the transition point for the various $S / C$ ratios. The groups that received common $S / C$ ratios were combined because two-tailed $t$ tests did not reveal any differences [all $t \mathrm{~s}(14)<1.3$ ]. There was no systematic effect of $S / C$ ratio on the number of cycles to the transition point for either the stimulus or temporal DRs. All of the groups learned both DRs early in training; the means ranged between 10 and 40 cycles. An analysis of variance (ANOVA) did not reveal any effect of stimulus versus temporal DR, $S / C$ ratio, or their interaction. The similarity of the number of cycles to reach the transition point for the stimulus and temporal DR indicates that there was no systematic delay in the acquisition of the temporal DR until after the acquisition of the stimulus DR had occurred. Partial correlation coefficients (see Data Analysis section) were calculated to assess the relationship between stimulus duration, cycle duration, and $S / C$ ratio and the number of cycles to criterion for the stimulus and temporal DRs. None of these correlations were significant, indicating that there was no systematic effect of $S / C$ ratio or its component intervals on the number of cycles required to reach the point of transition.

Asymptotic performance: Discrimination ratios. Both the exponential fits and the point of transition analyses indicated that there was no effect of $S / C$ ratio on the rate of learning of either the stimulus or the temporal DR. However, the exponential fits (see Table 1) did indicate that there were differences in the asymptotic DRs among the groups. To further assess any effect of $S / C$ ratio on asymptotic performance, the stimulus and temporal DRs before and after the transition point are plotted in the bottom panel of Figure 3 . The groups with common $S / C$ ratios were combined because two-tailed $t$ tests did not reveal any significant differences in performance [all $t \mathrm{~s}(14)<1.8$ ]. None of the pretransition stimulus and temporal DRs were above 0.5 , and they were similar at all $S / C$ ratios. The stimulus and temporal DRs after the transition point were above 0.5 at all $S / C$ ratios [all $t \mathrm{~s}(15)>4.2$, all $p \mathrm{~s}<.01]$. The temporal DRs were similar at all four $S / C$ ratios, but the stimulus DRs decreased as the $S / C$ ratio increased. An ANOVA revealed effects of stimulus versus temporal DR $[F(1,44)=6.1, p<.05]$, $S / C$ ratio $[F(3,44)=5.1, p<.01]$, and their interaction $[F(3,44)=14.0, p<.001]$. Pairwise Tukey HSD tests conducted at each $S / C$ ratio revealed that the stimulus DR was significantly lower than the temporal DR at the 66.7 $S / C$ ratio (Groups 120/180 and 60/90; Figure 3, bottom 
panel) and that the stimulus DR was significantly higher than the temporal DR at the $8.3 \mathrm{~S} / \mathrm{C}$ ratio (Group 15/ 180). The pattern of results from the ANOVA and post hoc analyses is consistent with a crossing of the posttransition stimulus and temporal DR functions, as seen in Figure 3 (bottom panel).

To assess the source of the effect of the $S / C$ ratio on the asymptotic stimulus DRs, partial correlations were conducted on the posttransition stimulus DRs produced by the individual rats with the variables of stimulus duration, cycle duration, and $S / C$ ratio (see Data Analysis section). Both the stimulus duration and the cycle duration were correlated with posttransition stimulus DRs (stimulus duration, $r=-.66, p<.001$; cycle duration, $r=$ $.43, p<.01$ ), but there was no relationship of $S / C$ ratio with stimulus DR $(r=.03)$ when stimulus and cycle duration were partialled out. The partial correlation coefficients indicate that the stimulus and cycle durations were the determinants of the asymptotic level of the stimulus DR, not the $S / C$ ratio.

Partial correlation analyses were also conducted on the asymptotic temporal DRs from the individual rats: There was no significant correlation between stimulus duration, cycle duration, or the $S / C$ ratio and the temporal DRs, indicating that timing was unaffected by either of the interval durations or their ratio.

Asymptotic performance: Response rates. The stimulus DR was calculated by dividing the response rate in the middle of the stimulus by the sum of the rates in the middles of the stimulus and nonstimulus (Equation 3a), so the effect of stimulus and cycle durations on the stimulus DR could be due to an influence on response rates in the stimulus, the nonstimulus, or both. The response rates in the stimulus and nonstimulus were analyzed to determine the effects of stimulus and cycle duration on these components of the stimulus DR. The mean response rates during the stimulus, averaged across all rats that received a given stimulus duration, were $24.2,22.8,11.0$, and 4.5 responses/min for the 15-, 30-, 60-, and 120-sec stimulus durations, respectively; there was a negative correlation between stimulus duration and response rate during the stimulus $(r=-.65, p<.001)$. The mean response rates during the nonstimulus, averaged across all rats that received a given cycle duration, were $4.9,2.2$, and 1.0 responses/min for the 90-, 180-, and 360-sec cycle durations, respectively; there was a negative correlation between cycle duration and the response rate in the nonstimulus period $(r=-.41, p<.01)$.

The effects of the stimulus and cycle durations on the response rates during the stimulus and nonstimulus periods, respectively, indicate that the effect of $S / C$ ratio on the stimulus DR was due to the separate control of the stimulus and cycle durations on the two components of the stimulus DR. For example, Groups 30/180 and 60/360 both had a $S / C$ ratio of 16.7 ; the posttransition stimulus DRs were 0.90 for Group 30/180 and 0.93 for Group 60/ 360 . However, Group 30/180 produced higher response rates in both the stimulus $[t(14)=4.0, p<.01]$ and nonstimulus $[t(14)=2.9, p<.05]$ than did Group 60/360.

Unfolding of the conditioned response in time: Local response rate functions. The stimulus and temporal DRs are based on only a small portion of the response stream over the cycle. For a closer examination of the effects of stimulus and cycle duration on responding during the stimulus and nonstimulus periods, local response rate functions were generated (see Data Analysis section). The top panels of Figure 4 present the local response rates over Blocks 5-8 of training. These blocks were chosen because they occurred just after the transition point for the stimulus and temporal DRs (top panel of Figure 3). In the top-left panel are response rates as a function of time since food during the nonstimulus period. Response rates were initially high (which was probably due to the consumption of the previously delivered food pellet), followed by a low-rate period of responding and then an increasing rate of responding until the time of stimulus onset. The slope and maximum rate of the increasing portion of the response rate function was related to the cycle duration. In Group 60/90 (Figure 4, large triangles), there was a sharp increase in response rate that began around $20 \mathrm{sec}$ after food delivery and continued until stimulus onset at $30 \mathrm{sec}$. The four groups with the $180-\mathrm{sec}$ cycle duration produced a moderately sloped function, and Group 60/360 produced the lowest slope. In the top-right panel of Figure 4 are response rates as a function of time since stimulus onset. The pattern of response rate functions during the stimulus was similar to those in the nonstimulus. There was an increasing response rate as a function of time, with shorter durations resulting in steeper slopes and higher maximum rates. The response patterns in both the nonstimulus and stimulus periods were present in many rats during the first four training blocks, but the temporal gradients were less sharp.

The response rate functions were also examined at asymptote (Blocks 21-40) to determine whether the observed timing in the nonstimulus and stimulus periods changed with further training. The same trend was observed: The shorter the interval (stimulus or cycle), the steeper the slope and higher the rate of responding. The one exception was Group 60/90, which no longer displayed an increasing response rate prior to stimulus onset (Figure 4, large triangles). There was one additional change in the response rate functions with further training: The three groups with a common stimulus duration of $60 \mathrm{sec}$ differed in slope and rate so that there were progressively lower slopes and response rates as the cycle duration increased. The source of this effect is discussed later.

Unfolding of the conditioned response in time: Slope analysis. To characterize the effects of interval duration on the form of the response rate function, the slope of each response rate function produced by each rat during the stimulus and nonstimulus periods was calculated. 


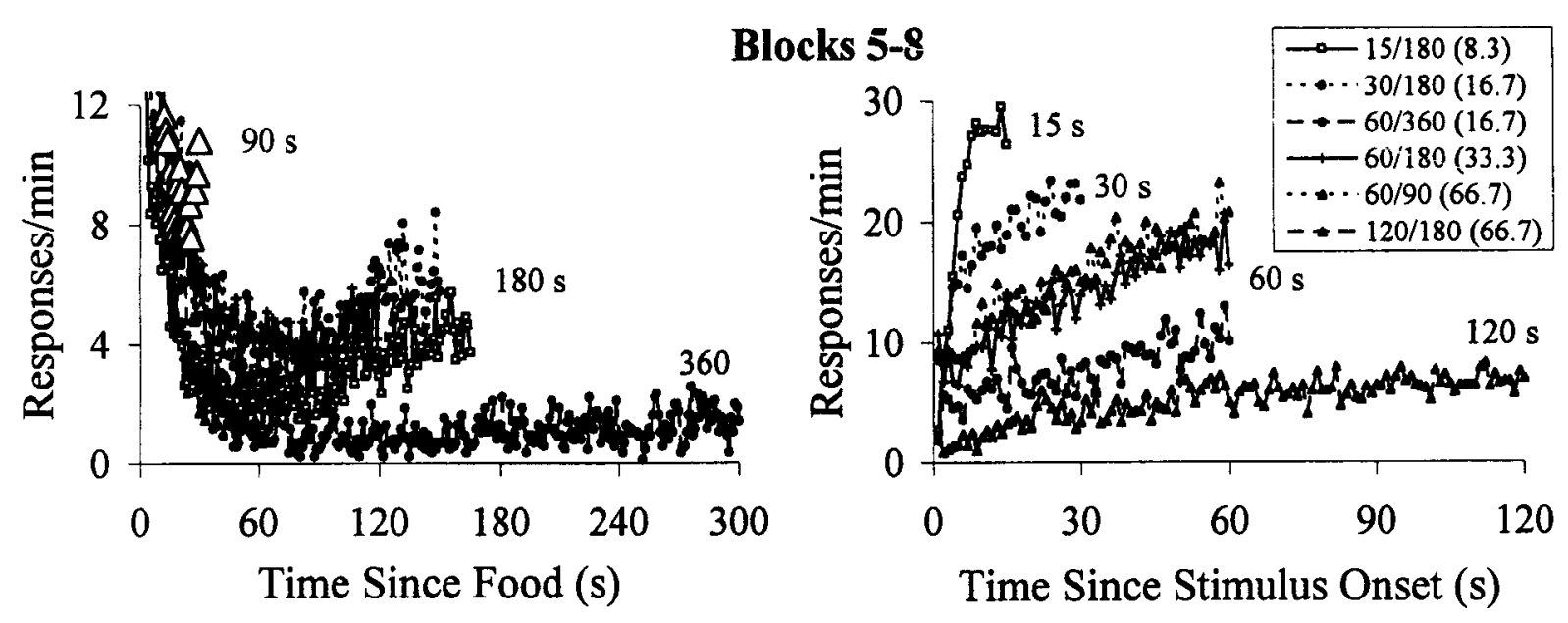

Blocks 21-40
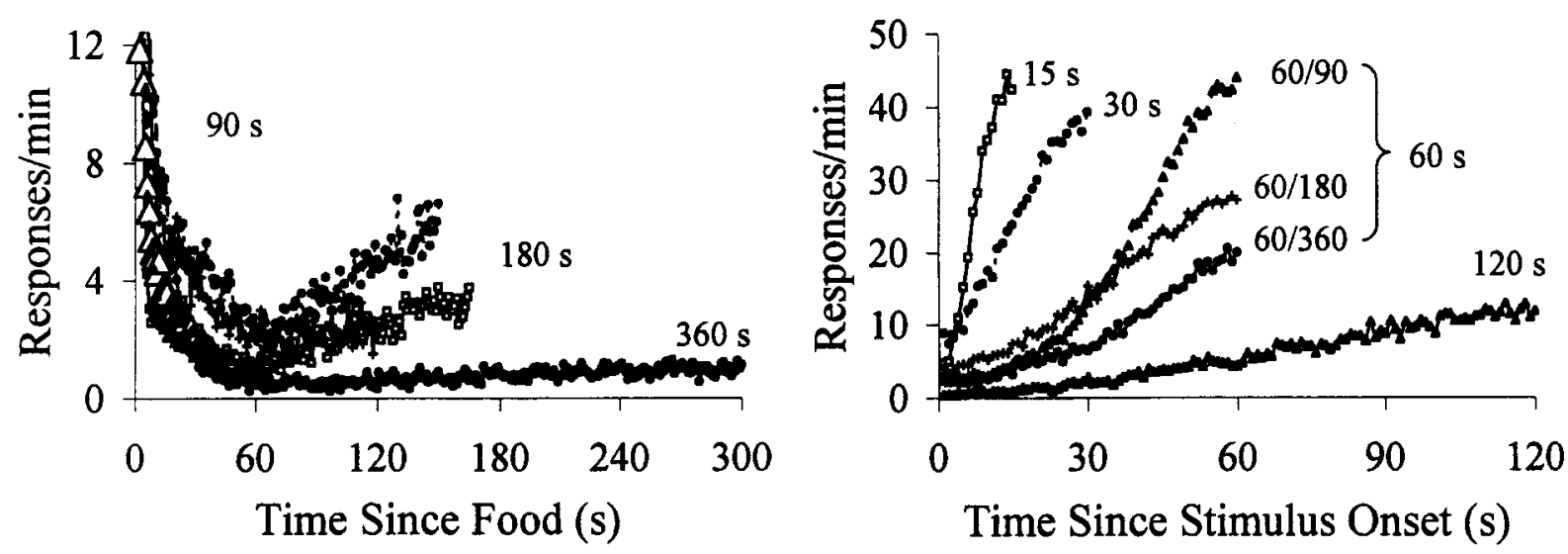

Figure 4. Response rate in responses/min as a function of time since food or stimulus onset over Blocks $5-8$ and Blocks $21-40$ of training. The vertical axis in the left panels was truncated at 12 responses/min to allow for better observations of the temporal gradients in the groups with low rates of responding. The cycle durations for the corresponding groups are labeled in the left panels. The stimulus durations are labeled in the right panels; the groups with a common stimulus duration of 60 sec are labeled individually in the bottom-right panel.

One slope was determined during the period from food delivery until stimulus onset (the nonstimulus period), and a second slope was determined during the period from stimulus onset until the next food delivery (the stimulus period). The response rate functions were fit with a linear equation that contained a single parameter of slope and an intercept equal to $\mathbf{0}$. (Initially, two-parameter fits were used, but the fits to the nonstimulus period required the removal of the first $20 \mathrm{sec}$ of the response rate function because of the high rate of food-cup checking due to the consumption of the previously delivered pellet.) The single-parameter fit provided a good approximation to the rising slope of the function when all of the data were used. The slope estimates of the one- and two-parameter linear fits were similar.

The log slopes of the fits during the stimulus and nonstimulus periods for each individual rat are displayed in Figure 5, with the top panel containing the fits from Blocks 5-8 and the bottom panel containing the fits from Blocks 21-40. The log slopes in the stimulus (Figure 5, closed diamonds) are plotted against log stimulus duration; the log slopes in the nonstimulus (Figure 5, open circles) are plotted against log cycle duration. Although the slopes from the stimulus and nonstimulus periods were obtained from different portions of the response rate function, they were adequately fit by a single linear function. A linear regression analysis revealed that $\log$ interval duration was a predictor of the log slope $\left[r^{2}=.78\right.$; overall model, $F(1,94)=325.9, p<.001]$ during Blocks $5-8$ of training, yielding a linear fit with a slope of -1.8 and an intercept of 2.6. The regression analysis, conducted on the slopes from Blocks $21-40$, also revealed a linear relationship with a slope of -2.2 and an intercept of $3.4\left[r^{2}=\right.$ .82 ; overall model, $F(1,94)=436.3, p<.001]$. The regression analysis indicates that there was a general effect of interval duration on the slope of the response rate function, regardless of whether timing was initiated by the previous food or stimulus onset event.

The slope analysis indicated that cycle duration affected responding during the nonstimulus; there also ap- 

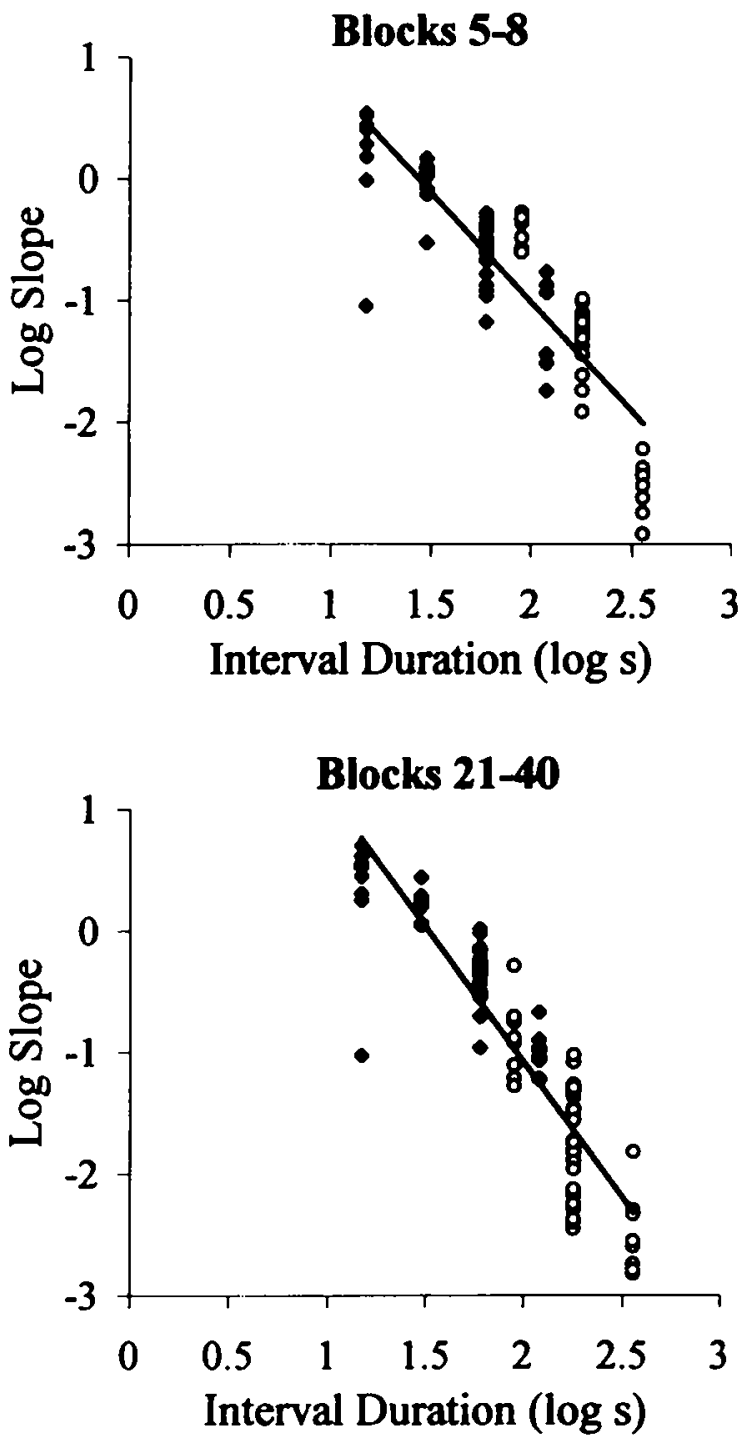

Figure 5. The log (base 10) slopes of the linear fits of the response rate functions versus tog (base 10 ) interval duration. Negative log slopes are linear slopes that were less than 1 . Slopes were obtained during both the stimulus period (filled diamonds) and the nonstimulus period (open circles) over Blocks 5-8 and Blocks 21-40 of training for each individual rat. The line through the data points is the best-fitting linear function obtained from a regression analysis.

peared to be an effect of cycle duration on responding during the stimulus in the three groups that received a stimulus duration of $60 \mathrm{sec}$ (bottom-right panel of Figure 4). Figure 6 shows that the slopes of the response rate functions during the stimulus were ordered with regard to cycle duration, so that the $90-, 180-$, and $360-\mathrm{sec}$ cycles produced progressively shallower slopes during the stimulus. A regression analysis disclosed a linear relationship between log cycle duration and log slope during the stimulus $[F(1,22)=12.55, p<.01]$ with a slope of -0.5 and an intercept of 0.8 .

\section{Stimulus Omission Tests}

The effect of cycle duration on responding during the stimulus implies that the rats were timing over the entire cycle duration. The stimulus omission tests provide a more direct characterization of responding over the entire cycle duration in the absence of the noise and the houselight. These tests were conducted following original training, by which point all groups of rats had achieved stable asymptotic performance for several sessions. The top panel of Figure 7 shows the response rate as a function of time since food during the stimulus omission tests. In all three groups, there was an initial high rate of responding (probably due to consumption of the previously delivered food pellet) followed by a near-zero rate of responding and then an increasing rate of responding. The increase was greatest for Group 60/90, which received the shortest cycle duration; the higher rates of responding during shorter cycle durations undoubtedly contributed to the observed increase in responding during the stimulus in Figures 4 and 6.

Linear functions were fit to the response rate curves to determine whether the observed timing during the cycle was comparable to the observed timing during the nonstimulus period at the end of training. These fits involved the single parameter of slope, with the intercept set to zero. The log slopes for the individual rats in each group are plotted against the log cycle duration in the bottom panel of Figure 7. The slopes were inversely related to the interval duration, as in original training (Figure 5). A re-

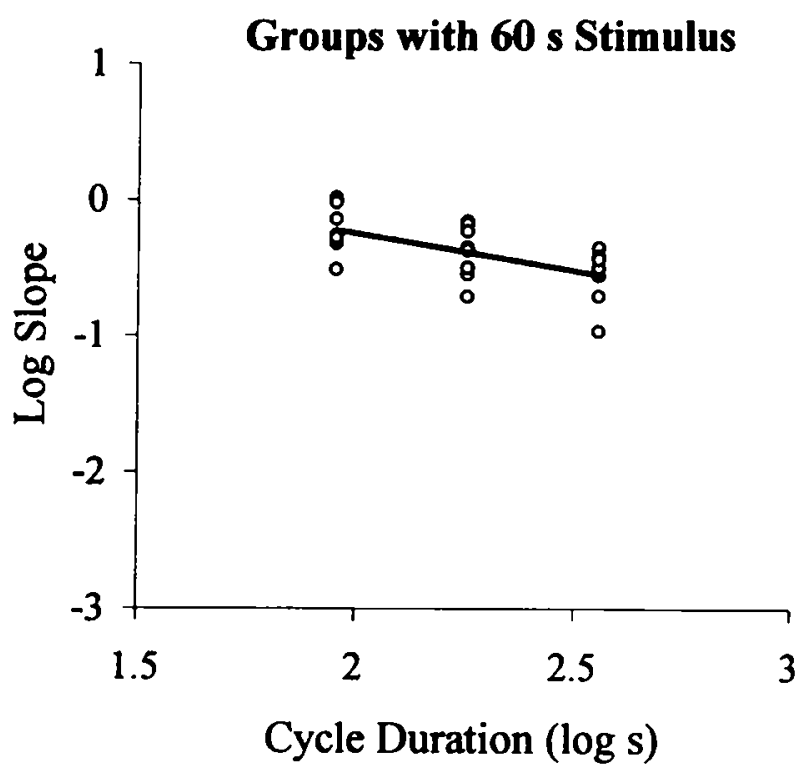

Figure 6. The $\log$ (base 10 ) slopes of the linear fits of the response rate functions (Blocks $21-40$ ) during the stimulus that were produced by the rats that received a common stimulus duration of $60 \mathrm{sec}$ but different cycle durations of 90,180 , and $360 \mathrm{sec}$. The log slopes are plotted against log (base 10) cycle duration. Negative log slopes are linear slopes that were less than 1. The solid line through the data points is the best-fitting linear function obtained from a regression analysis. 
gression analysis revealed that $\log$ cycle duration was a predictor of the log slope $\left[r^{2}=.70\right.$; overall model, $F(1,22)=52.3, p<.001]$, yielding a linear fit with a slope of -2.1 and an intercept of 2.8. The parameters of the regression analysis were similar to those obtained over Blocks 21-40 of training (bottom panel of Figure 5). There was no difference between the slopes that were fit to the nonstimulus period over Blocks $21-40$ and the slopes that were fit to the entire cycle in the stimulus omission tests $[F(1,23)<1]$.

\section{Peak Procedure Testing}

Following original training, the rats were given a peak procedure with nonreinforced peak interval durations that were four times the duration of the stimulus on reinforced occasions. Peak procedure testing was adminis-
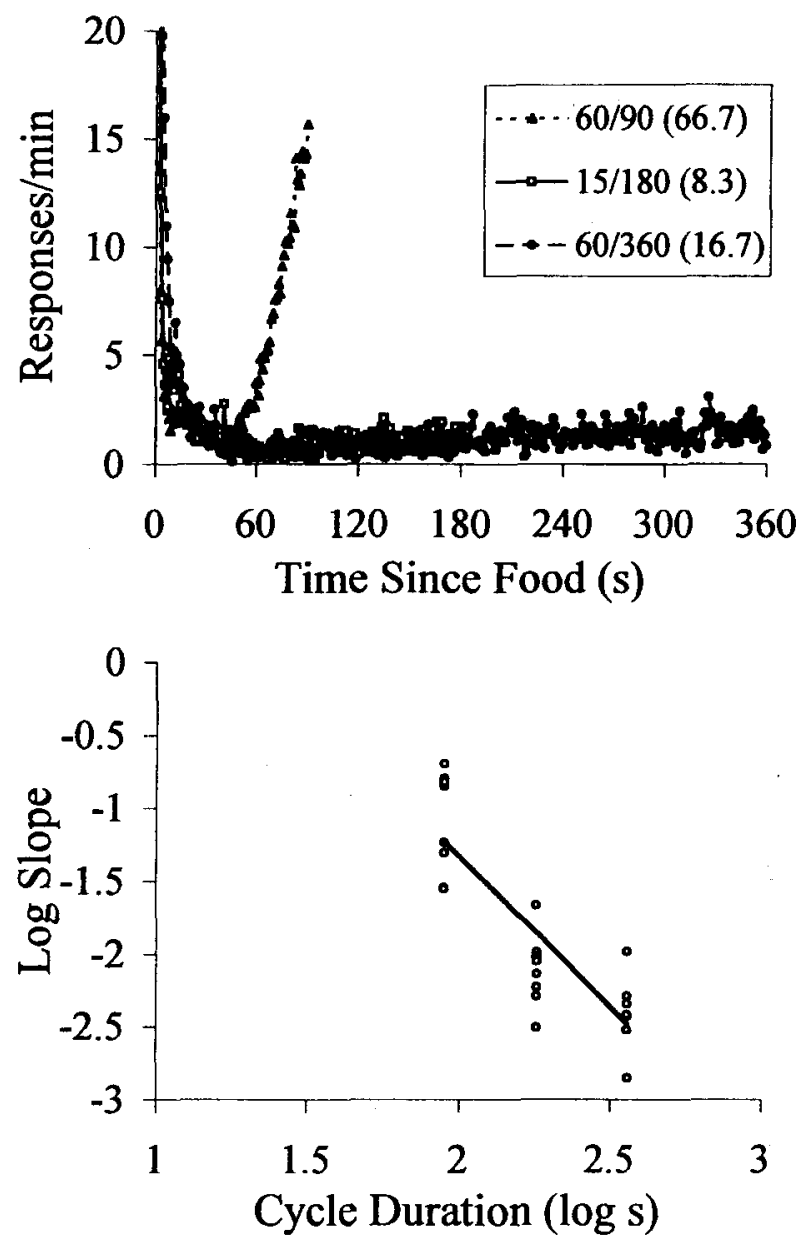

Figure 7. Top panel: Responses/min as a function of time since food during the stimulus omission tests, which were administered to Groups 60/90, 15/180, and 60/360. Bottom panel: The log (base 10) slopes of the linear fits to the response rate functions during the stimulus omission tests plotted against the log (base 10) cycle duration. Each point is the slope of the response rate function produced by an individual rat. Negative log slopes are linear slopes that were less than 1 . The solid line through the data is the best-fitting linear equation obtained from a regression analysis.
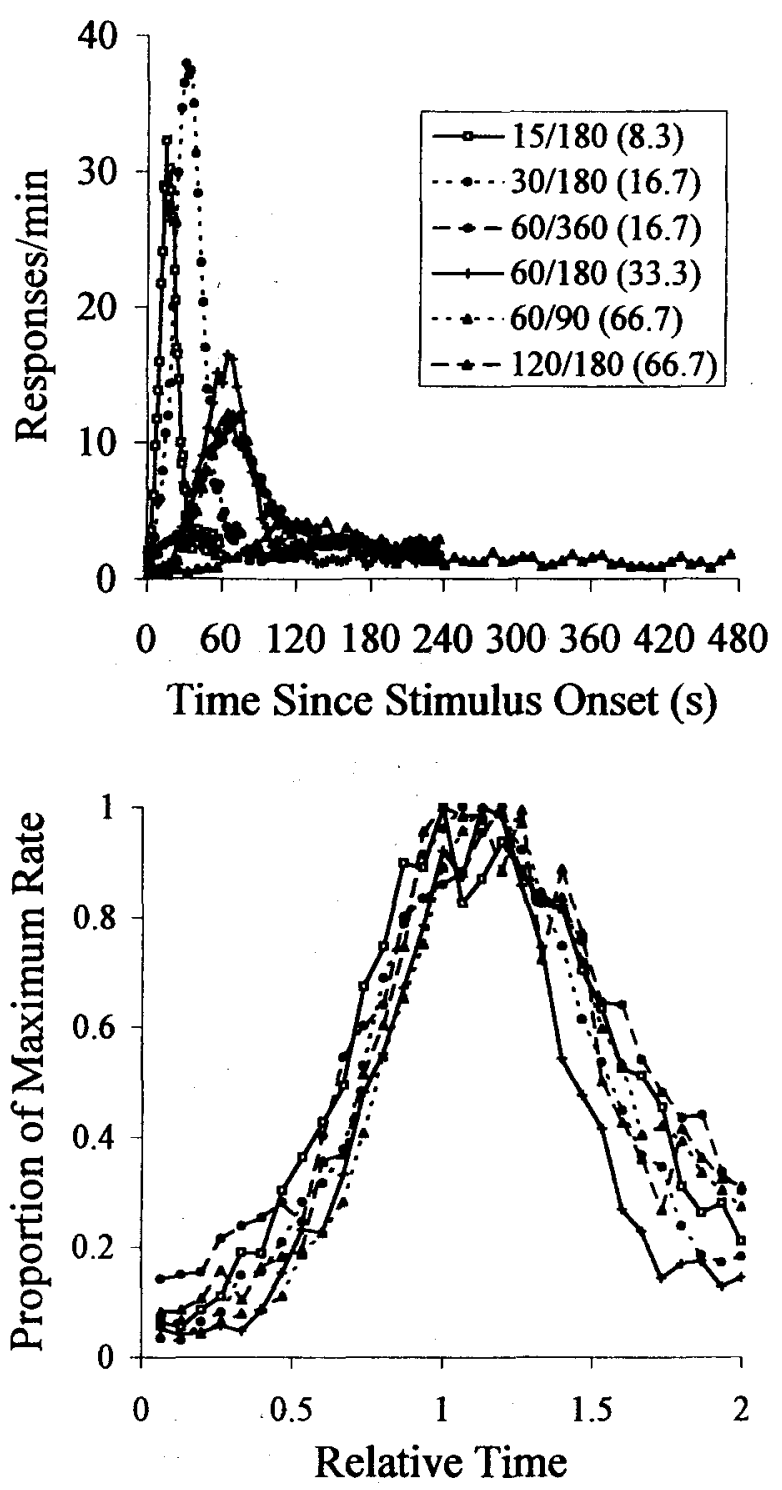

Figure 8. Top panel: Response rate in responses/min as a function of time since stimulus onset during the long unreinforced peak intervals for each group of rats. Bottom panel: The proportion of the maximum response rate as a function of relative time in the peak interval. Relative time was the proportion of the stimulus duration during training. Only the first half of the peak interval is displayed.

tered to determine whether the response rate functions would reach a maximum near the expected time of food delivery relative to stimulus onset. The local response rate functions for the six groups of rats are displayed in the top panel of Figure 8. All of the response rate functions peaked near the expected time of reinforcement, relative to stimulus onset. Shorter stimulus durations resulted in local response rate functions that were narrower and had higher peak rates than longer stimulus durations. The bottom panel of Figure 8 is a plot of the response rate functions from the top panel, but on a relative time scale 
(proportion of the training stimulus duration) and a relative rate scale (proportion of the maximum rate). The relative functions demonstrate that, when differences in the maximum rate are ignored, the response rate functions superpose in relative time, indicating that the width of the response rate function increased proportionately with the duration of the stimulus. Moreover, the relative functions indicate that, in all groups, the maximum rate occurred near the expected time of food delivery at a relative time of 1 .

\section{DISCUSSION}

In the delay conditioning procedures used in the present experiment, the rats changed their distribution of responses as a function of training. There was an increase in the rate of responding in the presence of the stimulus relative to its absence, as measured by the stimulus DR (top panel of Figure 2). There was also an increase in the response rate at the end of the stimulus relative to the beginning of the stimulus, as measured by the temporal DR (bottom panel of Figure 2).

The rates of learning of both the stimulus DR and the temporal DR as a function of the number of reinforcements were similar under all conditions. Although it was hypothetically possible for the stimulus DR to emerge before the temporal DR (top panel of Figure 1) or the temporal DR to emerge before the stimulus DR (middle panel of Figure 1), the two DRs instead emerged together (bottom panel of Figure 1). Typically, the point of transition from chance to above chance for the stimulus DR and the temporal DR occurred at about the same point in training (top panel of Figure 3). This concurrent emergence suggests that a timing mechanism may actively participate in the early stages of acquisition (see also Bevins \& Ayres, 1995; Gibbon et al., 1977; Holder \& Roberts, 1985; Holland, 2000; Maes \& Vossen, 1992).

There was no effect of the $S / C$ ratio on the slope of the exponential fits to the stimulus DRs as a function of training in Figure 2, but there was an inverse relationship between the $S / C$ ratio and the asymptote of the exponential fits (Table 1). Moreover, there was no effect of the $S / C$ ratio on the number of cycles to reach a point of transition from near-chance to near-asymptotic levels of the stimulus DR, but the $S / C$ ratio was inversely related to the posttransition stimulus DR (bottom panel of Figure 3). These results are not necessarily inconsistent with the common finding that the $S / C$ ratio is directly related to the number of cycles required to reach an absolute performance criterion (Gibbon et al., 1977; Gibbon \& Balsam, 1981; Lattal, 1999; Terrace et al., 1975). A problem with the use of an absolute performance criterion is that it fails to distinguish between the rate of learning and the asymptotic level. In fact, when an absolute criterion was used initially in the present study, there was an effect of the $S / C$ ratio on cycles-to-criterion. In most of the studies of the $S / C$ ratio effects on an absolute performance criterion (Gibbon et al., 1977; Lattal, 1999), asymptotic differences were reported, as in the present study. Thus, the reports of $S / C$ ratio effects on the number of trials to reach an absolute performance criterion may have been due to differences in asymptotic performance rather than differences in the rate of acquisition. In any event, the present results are problematic for a ratio comparison rule for acquisition of responding to the stimulus (Gallistel \& Gibbon, 2000; Gibbon \& Balsam, 1981), which proposes that the $S / C$ ratio affects the number of reinforcements required to pass a differential threshold for responding in the presence of a stimulus.

Although the $S / C$ ratio was negatively related to the stimulus DR, partial correlations indicated that this relationship was due to independent effects of the stimulus and cycle durations on the stimulus DR. Stimulus duration was negatively related to the stimulus DR, and cycle duration was positively related to the stimulus DR; there was no relationship between the $S / C$ ratio and the stimulus DR when the effects of the stimulus and cycle durations were partialled out. These results indicate that the stimulus and cycle durations themselves are the important contributors to the strength of conditioning that is observed, not the $S / C$ ratio, as has been previously reported (Gibbon et al., 1977; Lattal, 1999; Terrace et al., 1975). Consistent with the present report are Holland's (2000) data indicating the lack of $S / C$ ratio invariance in groups of rats that received a common $S / C$ ratio made up of different pairs of intervals. His results indicated that the stimulus and cycle durations contributed to the ultimate level of conditioning that was observed.

Further analyses of the stimulus and cycle duration effects on the stimulus DR revealed that the cycle duration was negatively related to the rate of responding in the nonstimulus and that the stimulus duration was negatively related to the rate of responding in the stimulus. These correlations appeared to be responsible for producing the effect of the stimulus and cycle durations on the strength of the stimulus DR. Shortening the stimulus duration, which results in a decrease in the $S / C$ ratio, increased the response rate during the stimulus. Because the stimulus DR was the rate during the stimulus divided by the sum of the rates in the stimulus and nonstimulus (see Equation 3a), an increase in the stimulus rate would increase the stimulus DR. On the other hand, shortening the cycle duration, which increases the $S / C$ ratio, increased the response rate in the nonstimulus period, thereby decreasing the stimulus DR. These effects have been previously reported in the rat goal-tracking paradigm (see Holland, 2000 , and Lattal, 1999, for comparable results), but they may differ somewhat from the results reported in pigeon autoshaping in which the strength of responding is assessed by the rate of keypecking during the stimulus, not by a stimulus discrimination ratio (Gibbon et al., 1977; Terrace et al., 1975).

The analysis of the temporal gradients revealed a possible source of the effects of the stimulus and cycle durations on the strength of the stimulus DR. Temporal gradients of responding were observed during both the 
stimulus period and the nonstimulus period. The strength (and slope) of responding during the stimulus was inversely related to the stimulus duration, and the strength (and slope) of responding during the nonstimulus was inversely related to the cycle duration. The slopes of responding in the stimulus and nonstimulus periods were characterized by a single linear function (on a log-log scale), suggesting that the interval durations were more important in determining the slope and rate of responding than were the events (CS or US) that marked the interval durations. The implication of these findings is that timing of the stimulus and cycle durations may be responsible for determining the strength of conditioning that is observed under any $S / C$ ratio.

The hypothesis that the rats timed the cycle duration was supported by the results of the stimulus omission test. Because the noise and the houselight were removed from both the stimulus period and the nonstimulus period, any timing that was observed on those probes must have been due to timing of the cycle duration that was initiated by the prior food delivery. In these tests, the rats produced an increasing response function over the entire cycle (Figure 7) that was indistinguishable from the response rate function observed in the nonstimulus interval during training (Figures 4 and 5).

Further evidence for timing of the stimulus duration came from the peak procedure test. The rats produced peaked response rate functions (Figure 8), with maximum rates near the time that food would normally occur, relative to stimulus onset and durations that superposed when plotted on relative time and relative rate scales (the scalar property of time perception; Church, Meck, \& Gibbon, 1994; Gibbon, 1977).

It is possible that the $S / C$ ratio may simply provide a rough assessment of the independent effects of the stimulus and cycle durations on responding. Although the $S / C$ ratio may be of some value for this purpose, it does not allow for same depth of prediction as the individual stimulus and cycle durations. Take, for example, Groups 30/ 180 and $60 / 360$, which both received a $S / C$ ratio of $1 / 6$. Although the strength of conditioning (the stimulus DR) was highly similar in the two groups, the rate and form of responding in the stimulus and nonstimulus periods differed dramatically. Knowledge of the shared $S / C$ ratio alone (without any information of the component durations) would not allow for any differential predictions in responding between these two groups.

Although timing and conditioning measures of responding were closely related, there are several aspects of the temporal DRs that remain to be explained. First is the lack of effect of the $S / C$ ratio or its component durations on the rate of learning or strength of the temporal $D R$. The lack of effect on the rate of acquisition indicates that the rate of learning of timing was unaffected by the duration of the interval that was timed, a result that is consistent with the notion that the timing mechanism was engaged at the same point in training in all groups. The lack of effect on the asymptotic temporal DRs may be due to the fact that, despite differences in rate and slope, all groups of rats had achieved equally good timing by the end of training. This is supported by the superposition of the response rate functions when plotted on relative time and relative rate scales (bottom panel of Figure 8). If a response rate function increases from near zero to a rate well above zero, the temporal DR would be near 1, regardless of the overall response rate.

Second is the observation that the temporal DRs continued to increase gradually long after the stimulus DRs had reached asymptote (Figure 2). The present set of analyses does not provide an explanation for this occurrence. One possibility is that the stimulus DR, which appeared to be produced by two temporal gradients, reached an asymptote once the temporal gradients were fairly well established and that additional small refinements in the temporal gradients had no effect on the overall level of the stimulus DR. This would be possible if the relative rate of responding in the middle of the stimulus and nonstimulus periods did not change appreciably with further refinements in the temporal gradients. One mechanism that might produce this would be a pivot point near the middle of each gradient, so that responding would decrease before the pivot point and increase after the pivot point but would remain approximately the same near the pivot point. Machado and Cevik (1998) reported that response changes in temporal gradients do occur around a pivot point at approximately $50 \%$ of the interval duration in the emergence of timing functions in operant procedures.

Given that timing and conditioning measures of responding were closely related in the present study and that timing emerged early in training, it seems necessary to consider the inclusion of timing mechanisms in theories of conditioning. There are three likely approaches: serial-, parallel-, and single-process models.

The serial-process model proposed by Gibbon and Balsam (1981) and extended by Gallistel and Gibbon (2000) asserts that conditioning occurs prior to the onset of timing via an independent process. The conditioning mechanism proposed by Gallistel and Gibbon is a comparator mechanism that estimates the rate of reinforcement during the stimulus relative to the rate of reinforcement in the background, using a ratio rule. If the relative rate of reinforcement in the stimulus is sufficiently better than the rate in the background, conditioned responding will occur. This comparison mechanism is sensitive to the $S / C$ ratio and produces a direct relationship between the $S / C$ ratio and the number of reinforcements to acquisition. According to Gallistel and Gibbon's model, it is the $S / C$ ratio that is the important determinant of the rate of acquisition, not the stimulus and cycle durations. A number of results in the present experiment were inconsistent with the Gallistel and Gibbon model. First, timing and conditioning appeared to emerge together in training, and the rate of emergence of timing was similar in all groups, which argues against a serial model in which conditioning occurs before timing. Of course, further study of the course of emergence of conditioning and timing will be 
necessary to determine the generality of these results. Second, the $S / C$ ratio effects were on the asymptotic level of conditioning, not on the rate of acquisition. Third, the $S / C$ ratio effects on the strength of conditioning (stimulus DR) were due to independent effects of the stimulus and cycle durations, not the $S / C$ ratio.

An alternative approach would be to assume that conditioning and timing are separate processes that occur in parallel. This approach was first described by Pavlov (1927) and continues in modern-day textbooks on animal learning and cognition (e.g., Roberts, 1998; Schmajuk, 1997). A parallel-process argument differs from the serialprocess approach (Gallistel \& Gibbon, 2000; Gibbon \& Balsam, 1981) because there is no assumption that conditioning must occur before timing.

In the present procedure, the stimulus duration is confounded with CS-US interval, and the cycle duration is confounded with the total amount of context exposure. It is possible that the response rate in the stimulus was determined by conditioning to the CS-US interval (Bitterman, 1964; Black, 1963; Gibbon et al., 1977; Salafia et al., 1975; Schneiderman \& Gormezano, 1964), and the response rate in the nonstimulus period was determined by conditioning to the context (Goddard \& Jenkins, 1988; Tomie, 1981). These two associative mechanisms could in principle produce higher response rates during the stimulus to shorter stimulus durations (right panels of Figure 4) and higher response rates during the nonstimulus to shorter cycle durations (left panels of Figure 4). While the rates of responding may have been determined by the conditioning mechanism, the form of responding would be determined independently by some timing mechanism.

While this parallel processing argument could explain both conditioning and timing to the stimulus, it does so by sacrificing parsimony in that two associative processes (excitatory conditioning to the stimulus and contextual conditioning to the experimental background) and one timing process are required to account for the results. Perhaps, more importantly, it fails to account for the multitude of timing results, which often appeared to relate to the conditioning that was observed.

A final approach would be a single process that produces conditioning and timing together. The single process may be a timing process or a real-time conditioning process (Blazis, Desmond, Moore, \& Berthier, 1986; Klopf, 1988; Moore \& Desmond, 1992; Moore et al., 1986; Sutton \& Barto, 1981, 1990; Tesauro, 1986). A single-process model may predict the observed pattern of results by assuming that the temporal DR reflects the absolute control of the stimulus duration over the slope of responding during the stimulus, and the stimulus DR reflects the relative control of the stimulus and cycle durations over timing in the stimulus and nonstimulus periods, respectively. Thus, the stimulus and cycle duration effects on the stimulus DR may be explained by simultaneous timing of the stimulus and cycle intervals.

To make the simultaneous temporal processing proposal more concrete, the following model was implemented: With a constant interval between an event (such as the delivery of food or the onset of a stimulus), the expected time until food decreases linearly. Thus, if food is presented $90 \mathrm{sec}$ after the onset of an auditory stimulus, the expected time until food is initially $90 \mathrm{sec} ;$ after $1 \mathrm{sec}$, the expectation is $89 \mathrm{sec}$; after $2 \mathrm{sec}$, it is $88 \mathrm{sec}$, and so on (the term expected time refers to the mean time to food). The response rate functions approximated this linear form, with a near-zero intercept. In particular, the response rate function appeared to be inversely related to the expected time until food. The response rate at any moment in time would be determined by the slope of the function multiplied by the time into the interval

$$
r_{d}=s_{d} t, \quad 0 \leq t \leq d,
$$

where $r$ is the response rate (in responses per minute), $s$ is the slope, $t$ is the time since the event, and $d$ is the duration between an event and a reinforcement (in seconds). These results were shown in Figure 4.

There was a negative relationship between the slope $(s)$ and the stimulus or cycle duration $(d)$ that was approximately

$$
\log _{10} s_{d}=-2 \log _{10} d+3 .
$$

This result was shown in Figure 5. The equation can also be written

$$
s_{d}=1,000 d^{-2} .
$$

Substituting $s_{d}$ from Equation $5 \mathrm{~b}$ into Equation 4,

$$
r_{d}=1,000 t d^{-2}, \quad 0 \leq t \leq d .
$$

The top panel of Figure 9 shows the response gradients that would be predicted on the basis of Equation 6 for intervals between 15 and $360 \mathrm{sec}$. They have two of the characteristics of the observed response gradients shown in Figure 4: the approximately linear increase in response rate as a function of time since event onset, and a slope that decreases as a function of the interval between event onset and food $(d)$.

The scalar property (see bottom panel of Figure 8) emerges naturally from Equation 6 . The maximum response rate occurs when $t=d$; at this time, the mean response rate is predicted to be $1,000 / d$. The relative rate of responding, by definition, is the absolute rate divided by the maximum rate. This is $t / d$ : The mean relative response rate is predicted to be the same if time $(t)$ is scaled relative to the duration of the constant interval $(d)$. This produces superposition of the functions from the onset of an event until the time of reinforcement. The superposition property is a pervasive and important result that guides and constrains quantitative theories of timing (Church et al., 1994; Gallistel \& Gibbon, 2000; Gibbon et al., 1984).

In most of the conditions, the rats had two intervals that preceded the delivery of reinforcement, the cycle and stimulus durations. Both of these are active during the stimulus period, only the cycle duration would be relevant in controlling responding in the nonstimulus period. For example, in Group 30/180, there was a stimulus du- 

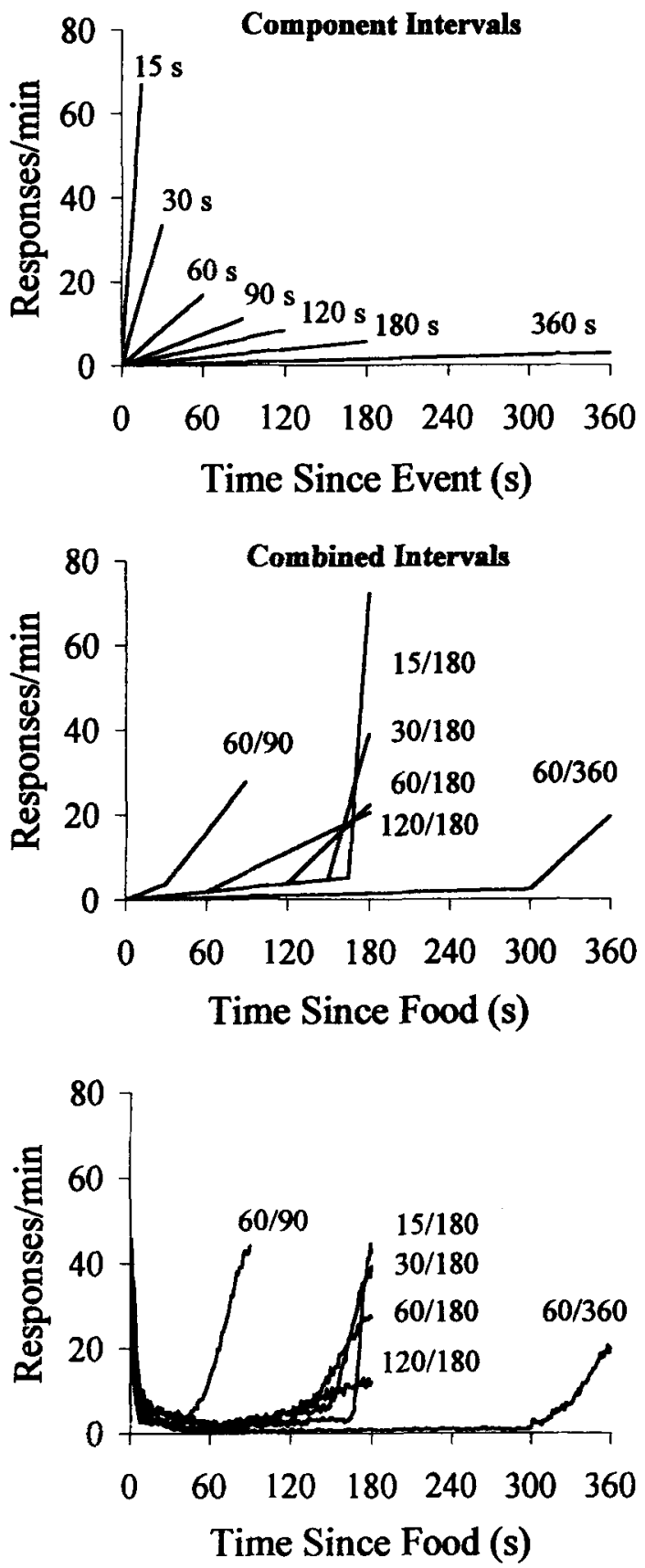

Figure 9. A simultaneous temporal processing model with an additive combination rule. Top panel: Linear basis functions for timing of the individual stimulus and cycle durations ranging from 15 to $360 \mathrm{sec}$, determined from Equation 6. Middle panel: The predicted combined response rate functions using summation of pairs of stimulus and cycle basis functions, plotted as a function of time since food. Bottom panel: The combined response rate functions produced by the rats, plotted as a function of time since food. These are the same data as in the bottom panels of Figure 4.

ration of $30 \mathrm{sec}$ and a cycle duration of $180 \mathrm{sec}$. During the first $150 \mathrm{sec}$ after food delivery, timing of the 180sec cycle duration from the previous food delivery could occur; during the last $30 \mathrm{sec}$, timing of both the $180-\mathrm{sec}$ cycle duration and the 30 -sec stimulus duration could occur. In the three groups that were trained with the 60 sec stimulus duration, but with different cycle durations, shorter cycle durations resulted in steeper slopes and higher rates of responding during the stimulus than did longer cycle durations (Figures 4 and 6). Responding to the cycle duration must have combined with responding during the stimulus duration when both durations were present. The combination rule for this simultaneous temporal processing may be approximated by the addition of response rates, which is shown in the middle panel of Figure 9.

The combined functions are a reasonable approximation to the response rate functions produced by the rats (bottom panel of Figure 9), which are replotted from the bottom panels of Figure 4 . The combined functions have 1,170 points, and a total of only two fitted parameters. This is the parameter controlling for responsiveness $(1,000)$ and the exponent $(-2)$, which may be the same for all constant intervals from event to reinforcement, potentially reducing the number of parameters to 1 . There are three key features present in both the predicted combined functions and the rat data: (1) When the stimulus duration was short relative to the cycle duration (e.g. Group 15/180), there was an abrupt change in slope following stimulus onset; (2) in the four groups with a common cycle duration of $180 \mathrm{sec}$, there was a crossover of functions during the terminal portion of the stimulus; and (3) the temporal gradient during the 60 -sec stimulus was inversely related to cycle duration (see Groups 60/90, $60 / 180$, and 60/360).

An equation that predicts response rate $\left(r_{d}\right)$ as a function of the time since event $(t)$ and time from event to reinforcement $(d)$ also predicts discrimination ratios. On the basis of Equation 6, one can calculate a predicted stimulus discrimination ratio and temporal discrimination ratio by calculating the predicted response rate during the different windows of time used in the discrimination ratios (Equations $3 a$ and $3 b$ ). Of course, an equation that predicted the discrimination ratios alone could not be used to predict response rate gradients.

The present analysis has some important limitations. It does not account for the consummatory (or reactive) responses that occur after the onset of food (left panels of Figure 4); it overestimates response rates of very short intervals (e.g., Figure 9, Group 15/180); it does not account for the ogival form of responding that may emerge with more training (e.g., Figure 9, Group 60/90), or the break and run form that may emerge on individual cycles (Schneider, 1969); and it does not provide a principled basis for a decrease in response rate after the expected time of reinforcement in a peak procedure (Figure 8). Moreover, the present account does not apply to response forms in which the maximum rate occurs near the beginning (e.g., Holland, 1980) or in the middle (e.g., Holland, 1980; Levey \& Martin, 1968; Smith, 1968) of an interval duration. Many of these concerns can be handled either by an increase in the number of parameters of a descriptive model or by the development and application of a process model. 
The essential interpretation of this simultaneous temporal processing approach is that rats can (1) time the interval between the presentation of successive reinforcers, (2) time the interval between stimulus onset and reinforcement, and (3) combine the two time intervals in some manner. Timing of individual cycle (e.g., Goddard, 1995; Lockhart, 1966; Maes \& Vossen, 1992; Pavlov, 1927; Williams, Frame, \& LoLordo, 1992) and stimulus (e.g., Baum \& Bindra, 1968; Lynch, 1973; Pavlov, 1927; Rescorla, 1967) durations has been reported in a variety of conditioning paradigms. The present results indicate that when both durations are present in the same procedure, they are both timed. Simultaneous temporal processing has been reported in both classical (Desmond \& Moore, 1991; Kehoe, Graham-Clarke, \& Schreurs, 1989; Millenson, Kehoe, \& Gormezano, 1977) and instrumental (Catania \& Reynolds, 1968; Leak \& Gibbon, 1995; Meck \& Church, 1984) procedures when there are two or more intervals between stimuli and reinforcers. Simultaneous timing of multiple intervals may prove to be an important determinant of the rate and form of responding in conditioning procedures.

Moore and Choi (1997) presented a variant of the temporal difference real-time conditioning model (Sutton \& Barto, 1990), which contained simultaneous timing that was produced by separate temporal cascades initiated by stimulus onset and termination. Each temporal cascade resulted in a gradient of associative strengths that were summed to produce the output. The model resulted in correct predictions that conditioned eyeblink responses are unimodal on training trials in a trace conditioning procedure, they are bimodal when longer duration probes are used, and the bimodal responses are of lower amplitude on the probe trials than on the training trials because the amount of summation is less when the two cascades are uncoupled (Desmond \& Moore, 1991). It is possible that a single-process model, such as the temporal difference real-time model, could be extended to account for the results of the present study.

Any model that successfully accounted for the temporal gradients as a function of training necessarily accounts for standard summary measures of conditioning, such as the rate of responding in the presence of the stimulus, the difference between responding during the stimulus and the nonstimulus, or the ratio of responding during the stimulus to the rate of responding in the nonstimulus. The fact that timing and conditioning emerged together suggests that the same process may be responsible for the acquisition of the temporal gradients and the summary measures of responding. For the interpretation of the results of the present experiment, it is not clear that separate theories of timing and conditioning are necessary (Kirkpatrick \& Church, 1998).

\section{REFERENCES}

BAKAN, D. (1954). A generalization of Sidman's results on group and individual functions, and a criterion. Psychological Bulletin, 51, 63-64.

Barnet, R. C., ARnOld, H. M., \& Miller, R. R. (1991). Simultaneous conditioning demonstrated in second-order conditioning: Evidence for similar associative structure in forward and simultaneous conditioning. Learning \& Motivation, 22, 253-268.

Barnet, R. C., Cole, R. P., \& Miller, R. R. (1997). Temporal integration in second-order conditioning and sensory preconditioning. Animal Learning \& Behavior, 25, 221-233.

BAUM, M., \& BINDRA, D. (1968). Conditioned incentive motivation, spontaneous behaviour, and inhibition of delay. Canadian Journal of Psychology, 22, 323-335.

Bevins, R. A., \& Ayres, J. J. B. (1995). One-trial context fear conditioning as a function of the interstimulus interval. Animal Learning \& Behavior, 23, 400-410.

BitTerman, M. E. (1964). Classical conditioning in the goldfish as a function of the CS-UCS interval. Journal of Comparative \& Physiological Psychology, 58, 359-366.

BLACK, A. H. (1963). The effects of CS-US interval on avoidance conditioning in the rat. Canadian Journal of Psychology, 17, 174-182.

Blazis, D. E. J., Desmond, J. E., Moore, J. W., \& Berthier, N. E. (1986). Simulation of the classically conditioned nictitating response by a neuron-like adaptive element: A real-time invariant of the SuttonBarto model. In Proceedings of the Eighth Annual Conference of the Cognitive Science Society (pp. 176-186). Hillsdale, NJ: Erlbaum.

Brown, P. L., \& Jenkins, H. M. (1968). Autoshaping of the pigeon's keypeck. Journal of the Experimental Analysis of Behavior, 11, 1-8.

CATANia, C. A., \& Reynolds, G. S. (1968). A quantitative analysis of the responding maintained by interval schedules of reinforcement. Journal of the Experimental Analysis of Behavior, 11, 327-383.

Church, R. M., Meck, W. H., \& Gibbon, J. (1994). Application of scalar timing theory to individual trials. Journal of Experimental Psychology: Animal Behavior Processes, 20, 135-155.

Cole, R. P., Barnet, R. C., \& Miller, R. R. (1995). Temporal encoding in trace conditioning. Animal Learning \& Behavior, 23, 144-153.

DESMOND, J. E., \& MOORE, J. W. (1991). Altering the synchrony of stimulus trace processes: Tests of a neural-network model. Biological $\mathrm{Cy}$ bernetics, 65, 161-169.

DOMJAN, M. (1980). Effects of the intertrial interval on taste aversion learning in rats. Physiology \& Behavior, 25, 117-125.

Dreyfus, L. R., FetTerman, J. G., Smith, L. D., \& StubBs, D. A. (1988). Discrimination of temporal relations by pigeons. Journal of Experimental Psychology: Animal Behavior Processes, 14, 349-367.

EsTES, W. K. (1956). The problem of inference from curves based on group data. Psychological Bulletin, 53, 134-140.

Fetterman, J. G., \& Dreyfus, L. R. (1986). Pair comparison of durations. Behavioural Processes, 12, 111-123.

Fetterman, J. G., \& Dreyfus, L. R. (1987). Duration comparison and the perception of time. In M. L. Commons, J. E. Mazur, J. A. Nevin, \& H. Rachlin (Eds.), Quantitative analyses of behavior: Vol 5. The effects of delay and intervening events on reinforcement value (pp. 327). Hillsdale, NJ: Erlbaum.

Gallistel, R., \& GibBon, J. (2000). Time, rate and conditioning. Psychological Review, 107, 289-344.

GibBon, J. (1977). Scalar expectancy theory and Weber's law in animal timing. Psychological Review, 84, 279-325.

Gibbon, J., Baldock, M. D., Locurto, C. M., Gold, L., \& Terrace, H. S. (1977). Trial and intertrial durations in autoshaping. Journal of Experimental Psychology: Animal Behavior Processes, 3, 264-284.

GibBon, J., \& Balsam, P. (1981). Spreading association in time. In C. M. Locurto, H. S. Terrace, \& J. Gibbon (Eds.), Autoshaping and conditioning theory (pp. 219-254). New York: Academic Press.

GibBon, J., \& ChURCH, R. M. (1984). Sources of variance in an information processing theory of timing. In H. L. Roitblat, T. G. Bever, \& H. S. Terrace (Eds.), Animal cognition (pp. 465-488). Hillsdale, NJ: Erlbaum.

Gibbon, J., Church, R. M., \& Meck, W. H. (1984). Scalar timing in memory. In J. Gibbon \& L. Allan (Eds.), Timing and time perception (Annals of the New York Academy of Sciences, Vol. 423, pp. 52-77). New York: New York Academy of Sciences.

GodDARD, M. J. (1995). Acquisition of US-noUS associations in Pavlovian conditioning. Learning \& Motivation, 20, 264-277.

GodDARD, M. J., \& JENKINS, H. M. (1988). Blocking of a CS-US association by a US-US association. Journal of Experimental Psychology: Animal Behavior Processes, 14, 177-186.

HAYS, W. L. (1997). Statistics. Forth Worth, TX: Holt, Rinehart, \& Winston. 
HoldER, M. D., \& RoberTs, S. (1985). Comparison of timing and classical conditioning. Journal of Experimental Psychology: Animal Behavior Processes, 11, 172-193.

Holland, P. C. (1980). CS-US interval as a determinant of the form of Pavlovian appetitive conditioned responses. Journal of Experimental Psychology: Animal Behavior Processes, 6, 155-174.

Holland, P. C. (2000). Trial and intertrial durations in appetitive conditioning in rats. Animal Learning \& Behavior, 28, 121-135.

Kehoe, E. J., Graham-Clarke, P., \& Schreurs, B. G. (1989). Temporal patterns of the rabbit's nictitating membrane response to com. pound and component stimuli under mixed CS-US intervals. Behavioral Neuroscience, 103, 283-295.

Kirkpatrick, K., \& ChurCh, R. M. (1998). Are separate theories of conditioning and timing necessary? Behavioural Processes, 44, 163182.

KLOPF, A. H. (1988). A neuronal model of classical conditioning. Psychobiology, 16, 85-125.

LatTal, K. M. (1999). Trial and intertrial durations in Pavlovian conditioning: Issues of learning and performance. Journal of Experimental Psychology: Animal Behavior Processes, 25, 433-450.

LEAK, T. M., \& GiBBON, J. (1995). Simultaneous timing of multiple intervals: Implications of the scalar property. Journal of Experimental Psychology: Animal Behavior Processes, 21, 3-19.

LEveY, A. B., \& Martin, I. (1968). Shape of the conditioned eyelid response. Psychological Review, 75, 398-408.

LOCKHART, R. A. (1966). Temporal conditioning of GSR. Journal of Experimental Psychology, 71, 438-446.

LYNCH, J. J. (1973). Pavlovian inhibition of delay in cardiac and somatic responses in dogs: Schizokinesis. Psychological Reports, 32, 13391349.

Machado, A., \& Cevik, M. (1998). Acquisition and extinction under periodic reinforcement. Behavioural Processes, 44, 237-262.

MaEs, J. H. R., \& Vossen, J. M. H. (1992). One-trial aversive conditioning to contextual cues: Effects of time of shock presentation on freezing during conditioning and testing. Bulletin of the Psychonomic Society, 30, 403-406.

Matzel, L. D., Held, F. P., \& Miller, R. R. (1988). Information and the expression of simultaneous and backward associations: Implications for contiguity theory. Learning \& Motivation, 19, 317-344.

MeCK, W. H., \& ChuRCh, R. M. (1984). Simultaneous temporal processing. Journal of Experimental Psychology: Animal Behavior Processes, 10, 1-29.

Millenson, J. R., Kehoe, E. J., \& Gormezano, I. (1977). Classical conditioning of the rabbit's nictitating membrane response under fixed and mixed CS-US intervals. Learning \& Motivation, 8, 351366.

Moore, J. W., \& ChoI, J.-S. (1997). The TD model of classical conditioning: Response topography and brain implementation. In J. W. Donahoe \& V. P. Dorsel (Eds.), Neural-networks models of cognition (pp. 387-405). New York: Elsevier Science.

MoORE, J. W., \& DEsmond, J. E. (1992). A cerebellar neural network implementation of a temporally adaptive conditioned response. In I. Gormezano \& E. A. Wasserman (Eds.), Learning and memory: The behavioral and biological substrates (pp. 347-368). Hillsdale, NJ: Erlbaum.

Moore, J. W., Desmond, J. E., Berthier, N. E., Blazis, D. E. J., SutTON, R. S., \& BARTO, A. G. (1986). Simulation of the classically conditioned nictitating membrane response by a neuron-like adaptive element: Response topography, neuronal firing, and interstimulus intervals. Behavioural Brain Research, 21, 143-154.

Pavlov, I. P. (1927). Conditioned reflexes (G. V. Anrep, Trans.). London: Oxford University Press.

Rescorla, R. A. (1967). Inhibition of delay in Pavlovian fear conditioning. Journal of Comparative \& Physiological Psychology, 64, 114-120.

Roberts, W. A. (1998). Principles of animal cognition. Boston: McGraw-Hill.
Salafia, W. R., Terry, W. S., \& Daston, A. P. (1975). Conditioning of the rabbit (Oryctolagus cuniculus) nictitating membrane response as a function of trials per session, ISI, and ITI. Bulletin of the Psychonomic Society, 6, 505-508.

Savastano, H. I., \& Miller, R. R. (1998). Time as content in Pavlovian conditioning. Behavioural Processes, 44, 147-162.

Schmajuk, N. A. (1997). Animal learning and cognition: A neural network approach. Cambridge: Cambridge University Press.

SCHNEIDER, B. A. (1969). A two-state analysis of fixed-interval responding in the pigeon. Journal of the Experimental Analysis of Behavior, 12, 677-687.

SCHNEIDERMAN, N., \& Gormezano, I. (1964). Conditioning of the nictitating membrane of the rabbit as a function of the CS-US interval. Journal of Comparative \& Physiological Psychology, 57, 188-195.

SIDMAN, M. (1952). A note on functional relations obtained from group data. Psychological Bulletin, 49, 263-269.

SмITH, M. C. (1968). CS-US interval and US intensity in classical conditioning of the rabbit's nictitating membrane response. Journal of Comparative \& Physiological Psychology, 66, 679-687.

SutTon, R. S., \& BarTo, A. G. (1981). Toward a modern theory of adaptive networks: Expectation and prediction. Psychological Review, 88, 135-170.

Sutton, R. S., \& Barto, A. G. (1990). Time derivative models of Pavlovian reinforcement. In M. R. Gabriel \& J. W. Moore (Eds.), Learning and computational neuroscience: Foundations of adaptive networks (pp. 497-537). Cambridge, MA: MIT Press.

TAtham, T. A., \& ZURN, K. R. (1989). The MED-PC experimental apparatus programming system. Behavioral Research Methods, Instruments, \& Computers, 21, 294-302.

Terrace, H. S., Gibbon, J., Farrell, L., \& Baldock, M. D. (1975). Temporal factors influencing the acquisition and maintenance of an autoshaped keypeck. Animal Learning \& Behavior, 3, 53-62.

TESAuro, G. (1986). Simple neural models of classical conditioning. Biological Cybernetics, 55, 187-200.

TomiE, A. (1981). Effects of unpredictable food on the subsequent acquisition of autoshaping: Analysis of the context blocking hypothesis. In C. M. Locurto, H. S. Terrace, \& J. Gibbon (Eds.), Autoshaping and conditioning theory (pp. 181-215). New York: Academic Press.

VOEKs, V. W. (1955). Acquisition of S-R connections: A test of Hull's and Guthrie's theories. Journal of Experimental Psychology, 47, 137147.

Williams, D. A., Frame, K. A., \& LoLordo, V. M. (1992). Discrete signals for the unconditioned stimulus fail to overshadow contextual or temporal conditioning. Journal of Experimental Psychology: Animal Behavior Processes, 18, 41-55.

\section{NOTES}

1. Because the session duration was 105 min for all groups of rats, Group $60 / 90$ received 68 cycles per session, Groups $15 / 180,30 / 180$, $60 / 180$, and 120/180 received 34 cycles per session, and Group 60/360 received 17 cycles per session. Therefore, a 17-cycle block was one fourth of a session in Group 60/90, one half of a session in Groups 15/ $180,30 / 180,60 / 180$, and $120 / 180$, and one session in Group 60/360. Only the first 40 blocks were included in the analysis.

2. The pattern of DRs produced by individual rats on successive trials may be quite different from the mean pattern of DRs. For example, the mean of a large number of individual functions, each of which abruptly changes from zero to one at a variable trial, may be a gradually increasing function (Sidman, 1952). The inferences that can be made about individual acquisition functions from mean functions have been described by Bakan (1954) and Estes (1956). Such all-or-none performance may be characteristic of much learning of humans (e.g., Voeks, 1955), as well as other animals (e.g., Terrace et al., 1975).

(Manuscript received November 2, 1999; revision accepted for publication June 14,2000 .) 